\title{
Chemical Kinetic Insights into the Octane Number and Octane Sensitivity of Gasoline Surrogate Mixtures
}

\author{
Eshan Singh, ${ }^{*}+\odot$ Jihad Badra, ${ }^{\ddagger}$ Marco Mehl, ${ }^{\S}$ and S. Mani Sarathy, ${ }^{* \dagger}$ \\ ${ }^{\dagger}$ King Abdullah University of Science and Technology (KAUST), Clean Combustion Research Center (CCRC), Thuwal 23955-6900, \\ Saudi Arabia \\ ${ }^{\ddagger}$ Saudi Aramco Research and Development Center, Fuel Technology R\&D Division, Dhahran 31311, Saudi Arabia \\ ${ }^{\S}$ Lawrence Livermore National Laboratory, Livermore, California 94550, United States
}

\section{Supporting Information}

\begin{abstract}
Gasoline octane number is a significant empirical parameter for the optimization and development of internal combustion engines capable of resisting knock. Although extensive databases and blending rules to estimate the octane numbers of mixtures have been developed and the effects of molecular structure on autoignition properties are somewhat understood, a comprehensive theoretical chemistry-based foundation for blending effects of fuels on engine operations is still to be developed. In this study, we present models that correlate the research octane number (RON) and motor octane number (MON) with simulated homogeneous gas-phase ignition delay times of stoichiometric fuel/air mixtures. These correlations attempt to bridge the gap between the fundamental autoignition behavior of the fuel (e.g., its chemistry and how reactivity changes with temperature and pressure) and engine properties such as its knocking behavior in a cooperative fuels research (CFR) engine. The study encompasses a total of 79 hydrocarbon gasoline surrogate mixtures including 11 primary reference fuels (PRF), 43 toluene primary reference fuels (TPRF), and 19 multicomponent (MC) surrogate mixtures. In addition to TPRF mixture components of iso-octane/ $n$-heptane/toluene, MC mixtures, including $n$-heptane, iso-octane, toluene, 1-hexene, and 1,2,4-trimethylbenzene, were blended and tested to mimic real gasoline sensitivity. ASTM testing protocols D-2699 and D-2700 were used to measure the RON and MON of the MC mixtures in a CFR engine, while the PRF and TPRF mixtures' octane ratings were obtained from the literature. The mixtures cover a RON range of $0-100$, with the majority being in the $70-100$ range. A parametric simulation study across a temperature range of $650-950 \mathrm{~K}$ and pressure range of $15-50$ bar was carried out in a constant-volume homogeneous batch reactor to calculate chemical kinetic ignition delay times. Regression tools were utilized to find the conditions at which RON and MON best correlate with simulated ignition delay times. Furthermore, temperature and pressure dependences were investigated for fuels with varying octane sensitivity. This analysis led to the formulation of correlations useful to the definition of surrogates for modeling purposes and allowed one to identify conditions for a more in-depth understanding of the chemical phenomena controlling the antiknock behavior of the fuels.
\end{abstract}

\section{INTRODUCTION}

Reducing emissions from transportation is imperative due to the challenges of climate change and the increasing demand for mobility. Transportation, alone, consumes around $57 \%$ of the total oil produced annually, and the numbers are rising with growing economies in India and China. Improving the efficiency of vehicles is the most feasible way to meet evermore stringent norms to reduce tailpipe $\mathrm{CO}_{2}$ and increasing demand for transportation fuels. Spark ignited engines operating on gasoline fuels are the primary technology for light duty passenger vehicles, ${ }^{1}$ and their efficiency is limited by knocking. ${ }^{2-4}$ Knocking is a form of abnormal combustion due to autoignition of the end-gas ahead of the spark-initiated flame front. ${ }^{5}$ The knocking tendency depends on the temperature and pressure of the end-gas and the fuel/air mixture's resistance to autoignition.

Researchers have quantified the knocking tendency of fuels based on octane number $(\mathrm{ON})$. A higher $\mathrm{ON}$ indicates a higher resistance to knock, which enables a fuel not to be limited by knock when operating at maximum efficiency operating conditions (e.g., advanced spark timings or increased compression ratio). The realization of knock at higher engine speeds and loads led to the formulation of the motor octane number (MON) standard test methodology, the current version of which was approved in 1968., ${ }^{6,7}$ The MON methodology uses a primary reference fuel (PRF) mixture of pure $n$-heptane and iso-octane as the 0 and 100 values on the scale, respectively, first proposed by Graham Edgar in 1927. ${ }^{8}$ The test fuel is run in a CFR engine (originally made by Waukesha in 1928) with a displacement of 611 c.c. at an air inlet temperature of $38{ }^{\circ} \mathrm{C}$ and fuel-air mixture heated to 149 ${ }^{\circ} \mathrm{C}$. The engine is run at 900 revolutions per minute (RPM), and the mixture (volumetric composition) of iso-octane in $n$ heptane that mimics the knocking behavior of the test fuel quantifies its MON. For example, a MON of 90 indicates that the test fuel is giving knocking behavior similar to that of $90 \%$ iso-octane and $10 \% n$-heptane $(\mathrm{v} / \mathrm{v}) .^{7}$ With a push towards improved efficiency by increasing compression ratios, knocking issues were realized at lower loads and speeds, and hence a more relaxed standard, called research octane number (RON), ${ }^{6}$

Received: October 13, 2016

Revised: January 11, 2017

Published: February 1, 2017 
was used to explain the knocking tendency at $600 \mathrm{rpm}$ and intake air mixture temperature of $52{ }^{\circ} \mathrm{C}$.

RON and MON are used ubiquitously; nevertheless, their application to fuels in modern engines is questionable, as the evolution of automobiles has pushed engine designs and operating conditions further away from the standard RON and MON test conditions. ${ }^{10}$ Moreover, the standard tests do have some caveats when using them to test the autoignition tendency of fuels. The standard CFR engine employs a carburetor for fuel-air mixing, which is not the most reliable and accurate method to maintain a stoichiometric air-fuel ratio. The shift from carburetors to port fuel injection occurred decades ago, and modern engines increasingly rely on direct fuel injection. In the CFR engine, residual gases vary from cycle-to-cycle, and the amount and composition of the residual gas can vary with engine compression ratio. Recent work has shown that $\mathrm{NO}$ in the CFR residual gas can affect the autoignition tendency of the fuel/air mixture. ${ }^{11,12}$ The effect of charge cooling is another nonideality that has been discussed in the literature. ${ }^{13-15}$ RON measurements define intake air temperature, while MON measurements fix the carburetor inlet air as well as outlet air-fuel mixture temperature. Any fuel with a high latent heat of vaporization (e.g., ethanol) shows a higher octane sensitivity, because in RON tests, there is ample cooling of the intake air when fuel is inducted. This leads to a lower carburetor outlet air-fuel mixture temperature when compared to a reference fuel with a lower latent heat of vaporization (e.g., PRF mixture), and hence a higher RON. ${ }^{13-15}$ This charge cooling effect introduces octane sensitivity irrespective of chemical kinetic effects. Finally, octane numbers higher than 100 were initially measured by testing the compression ratio limit for the test fuel matching with grams-per-liter of tetra ethyl lead (TEL) added to pure iso-octane. There is a higher uncertainty in $\mathrm{ON}$ measurements for fuels having ON higher than 100 .

As explained by Kalghatgi, ${ }^{16-18}$ modern engines generally operate in "beyond RON" conditions, and thus the use of octane index (OI) is more appropriate to quantify the antiknock quality of fuels in modern engines. The $\mathrm{OI}$ is unique because it accounts for the in-cylinder conditions, which vary depending on engine design and operating conditions. A major advantage of using $\mathrm{OI}$ is that it uses RON and MON as its base points, and hence builds on an established library of octane ratings. The OI is defined as in eq 1 :

$$
\mathrm{OI}=(1-K) * \mathrm{RON}+K^{*} \mathrm{MON}=\mathrm{RON}-K^{*} S
$$

The difference between RON and MON is known as the octane sensitivity $(S=\mathrm{RON}-\mathrm{MON})$. It can be understood as a measure of the difference between the autoignition chemistry of the fuel as compared to PRF. A gasoline (with $S>0$ ) will have different $\mathrm{OI}$ at different conditions. $K$ is an empirical constant that depends on the pressure and temperature history of the unburned mixture in the cylinder, and, in principle, on the combustion strategy adopted in the engine (e.g., direct injection, homogeneous or stratified compression ignition, etc.). Kalghatgi ${ }^{16-18}$ has shown that modern engines operate at highly negative $K$ values, so a fuel with a higher $S$ increases the OI (eq 1), enabling a higher compression ratio, and hence higher efficiency.

A fundamental understanding of the effect of mixture composition on octane sensitivity can help design fuel mixtures that improve engine efficiency. This requirement of higher sensitivity fuels for modern and future cars has recently garnered research interest. A recent publication by Westbrook et al. ${ }^{19}$ explains the fundamental effects of molecular structure on fuel sensitivity. That paper describes the effect of electron delocalization in low temperature reactivity and its effect on imparting fuel sensitivity for various classes of compounds (e.g., paraffins, olefins, aromatics, and alcohols). The understanding of the low temperature fuel chemistry and the use of modeling and computations has helped to pave the way for a better understanding of knocking phenomena of various fuels. However, studying a gasoline stream requires accounting for the whole spectrum of compounds present in the fuel. The compounds vary depending on the source of crude oil and the refining processes, which are dictated by nation-specific fuel specifications. ${ }^{20}$ Today, the fuel community has a solid qualitative understanding of the antiknock behavior of different classes of components at conditions relevant to commercial engines, and quantitative empirical correlations have been developed to assist the formulation of commercial gasolines. Daly et al. ${ }^{21}$ used spectroscopic techniques to account for the effect of functional groups in predicting RON values of pure compounds as well as 134 mixtures meant to mimic autoignition behavior of FACE gasolines. Abdul Jameel et $\mathrm{al}^{22}$ also recently demonstrated that fuel autoignition quality could be predicted from functional groups measured by nuclear magnetic resonance (NMR) spectroscopy. Early reports by Lovell attempted to correlate the octane ratings of 325 hydrocarbons with their structure. ${ }^{23}$ The $\mathrm{ON}$ values of pure hydrocarbons were used by Pera and Knop ${ }^{6}$ to determine the $\mathrm{ON}$ of TPRF mixtures using a linear-by-mole blending rule. Ramadan et al. ${ }^{24}$ proposed a polynomial fit for ethanol blended in PRFs and TPRFs, in an attempt to provide an empirical relationship for the nonlinearity observed in ethanol-gasoline blends. Ghosh et al. ${ }^{25}$ provided a relationship based on the ON of lumped hydrocarbons based on the composition of various refinery streams used to make gasoline. Other works using composition determination from GC deal with nonlinear weighing factor-based correlations, ${ }^{26}$ and several rely on linear relationships in blending octane number (BON). ${ }^{27-29}$ In summary, several authors have previously proposed ways to relate the octane rating to other measurable or observable chemical parameters.

Detailed kinetic modeling can provide further insights into the fundamental processes defining the reactivity of fuels in engines and help the synergistic design of future fuels and powertrains. To facilitate computations, there is a need for mixtures with a limited number of components that can replicate the physical and chemical behavior of gasoline. These mixtures of compounds are called "surrogates". They serve a two-fold purpose: to ease the modeling of chemistry and to facilitate replication of experiments across various facilities and at different times. Surrogates have been widely used to replicate the knocking behavior of real fuels.

PRF mixtures are among the simplest surrogates to characterize the knocking characteristics of fuels under specific engine operating conditions. However, the definition of $n$ heptane and iso-octane as lower and upper limits, respectively, of the octane rating in both RON and MON tests indicates that they have zero $S$, by definition. Gasoline fuels are not completely paraffinic in nature and hence have $S>0$ (i.e., typically in the range of 7-11). Moreover, it is evident that real gasoline does not have iso-octane or $n$-heptane as its major constituent; far from it, they are not even the dominant branched or straight paraffins. ${ }^{30,31}$ A simple surrogate used to 
emulate fuels with sensitivity $(S>0)$ comprises toluene, $n$ heptane, and iso-octane and is termed toluene primary reference fuels (TPRF). Adding further components to the surrogate is often useful to match the thermodynamic and kinetic properties and emission behavior of gasoline fuels. $^{15,32,33}$ Mehl et al. ${ }^{34,35}$ considered four component surrogate formulations (TPRF plus 2-pentene or 1-hexene) and found an agreeable match with RD387 gasoline in rapid compression machine (RCM), shock tube, and jet-stirred reactor (JSR) experiments. Perez and Boehmen ${ }^{36}$ advocated the use of a five-component surrogate for RD387, adding methylcyclohexane to Mehl et al.'s ${ }^{33}$ surrogate mixture. The autoignition tendency, tested in an ignition quality tester (IQT) and homogeneous charge compression ignition (HCCI) engine, was well matched. The added compounds, 1-hexeneand methylcyclohexane, however, had a minor effect in altering the ignition delay. Sarathy et al. ${ }^{37}$ used six-component surrogates to match the ignition characteristics of alkane-rich FACE (Fuels for Advanced Combustion Engines) gasolines, adding iso-pentane, 2-methylhexane, and $n$-butane to conventional TPRF mixtures. Recently, Ahmed et al. ${ }^{38}$ proposed an algorithm to match both ignition delay and fuel physical properties, which becomes increasingly important in modern direct injected engines. Sarathy et al. ${ }^{39}$ also utilized surrogates with up to nine components to study the effects of chemical composition on the ignition and octane sensitivity of FACE gasolines. Their analysis indicated that $n$-butane and $n$-heptane represent the carbon number range of paraffins, while 2methylbutane (iso-pentane), 2-methylhexane, and 2,2,4-trimethylpentane (iso-octane) appropriately represent the isoparaffins. Toluene and 1,2,4-trimethylbenzene account for much of the aromatics in gasolines. 1-Hexene is representative of the olefinic content in gasolines, as it captures the average carbon number and double bond position of olefins in gasolines. $^{39}$

The development of novel combustion strategies like compressed autoignition (CAI) and HCCI has imparted immense knowledge on the effect of fuel chemistry on its autoignition, and hence fuel's knocking tendency. ${ }^{30}$ These studies have finally been able to relate octane ratings to readily measurable and more absolute quantities. Curran et al. ${ }^{40}$ proposed an empirical relation between critical compression ratio and ON. Mehl et al. ${ }^{41}$ proposed a relation of anti knock index $(\mathrm{AKI}=(\mathrm{RON}+\mathrm{MON}) / 2)$ with ignition delay times (IDT) calculated at $825 \mathrm{~K}$ and 25 bar. Griffiths et al. ${ }^{42}$ correlated the ignition delay time of PRFs from RCM experiments and their composition (corresponding to the octane number) at $900 \mathrm{~K}$. They found quantitative agreement for low RON fuels (up to RON 85). Sarathy et al. ${ }^{43}$ tried to relate RON values to homogeneous gas-phase ignition delay times at $835 \mathrm{~K}$ and 20 bar. Badra et al. ${ }^{44}$ considered various TPRF mixtures and developed correlations of simulated ignition delay time with RON and MON using both constant volume and variable volume reactor simulations. The aforementioned studies have demonstrated that a link exists between kinetically driven ignition delay under idealized homogeneous reactor conditions and fuel $\mathrm{ON}$ measured in a CFR engine.

The current work aims to improve our fundamental understanding of the relationship between fuel composition and antiknock quality. In this context, the current work aims to measure the ON of different surrogate mixtures (PRF, TPRF, and multicomponent mixtures with 1-hexene and 1,2,4- trimethylbenzene) in a conventional CFR engine. IDT values for the mixtures are simulated in a homogeneous gas-phase reactor using a detailed chemical kinetic model. The purpose of conducting these idealized simulations is to find a pressure and temperature condition wherein IDT strongly correlates with measured RON and MON of each mixture. Once the correlation is established, simulation results at the chosen condition are interrogated to provide chemical kinetic insights into the effects of mixture composition on octane number and octane sensitivity.

\section{METHODOLOGY}

2.1. Mixture Preparation and Testing. To extend the understanding of gasoline surrogate molecule-molecule interactions, multicomponent surrogates were formulated and tested in this work. Surrogate molecules that are relevant to the various classes in gasoline are considered here. The iso-paraffins (iso-octane), $n$-paraffins ( $n$ heptane), aromatics (toluene and 1,2,4-trimethylbenzene), and olefins (1-hexene) have been mixed together in a systematic way, and their RON and MON were measured in the CFR engine in Saudi Aramco Research and Development Center (R\&DC). The RON and MON of the pure components are listed in Table 1. It should be noted how the

Table 1. RON, MON, and Octane Sensitivity of Pure Compounds Used in This Study

\begin{tabular}{llll}
\multicolumn{1}{c}{ species } & \multicolumn{1}{c}{ RON } & \multicolumn{1}{c}{ MON } & $\begin{array}{c}\text { octane } \\
\text { sensitivity }\end{array}$ \\
$\begin{array}{llll}\text { 2,2,4-trimethylpentane (iso- } \\
\text { octane) }\end{array}$ & $100^{a}$ & $100^{a}$ & 0 \\
$\begin{array}{l}n \text {-heptane } \\
\text { toluene }\end{array}$ & $0^{a}$ & $0^{a}$ & 0 \\
$\begin{array}{l}\text { 1-hexene } \\
\text { 1,2,4-trimethylbenzene }\end{array}$ & $118^{a} 124^{b}$ & $103,^{a} 112^{b}$ & $14.2,12$ \\
& $76.4^{c}$ & $63.4^{c}$ & 13.1 \\
& $1202^{d}$ & $110,^{d} 124^{b}$ & $10.2,24$ \\
& $148^{b}$ & &
\end{tabular}

${ }^{a}$ RON and MON from Ghosh et al. ${ }^{25}{ }^{b}$ ASTM Special Technical Publication No. 225. ${ }^{c}$ RON and MON from Mehl et al. ${ }^{34,47}{ }^{d}$ RON and MON from API. ${ }^{45,46}$

octane numbers reported in the literature for some of the most unreactive fuels components such as toluene and trimethylbenzene can vary depending on the measurement source. These fuels are less reactive than the iso-octane reference fuel used to define the octane rating, so blending a lower PRF with tetraethyllead (TEL), or other similar blending methodologies, are often used to assess their antiknock performance. This procedure produces different results depending on the amount of fuel added to the base fuel, the basis used to extrapolate the octane index for the pure component (e.g., volume vs mole based), and the base fuel composition used in the mixture.

First, high octane $(\mathrm{HO}) \mathrm{RON}=91$ and low octane (LO) $\mathrm{RON}=$ 70 fuels were chosen for this study. The two base fuels are PRF91 and PRF70. Second, toluene, 1-hexene, and 1,2,4-trimethylbenzene were added to the base fuels while maintaining the target RON by changing the percentages of iso-octane and $n$-heptane. The RON and MON of three-component mixtures were calculated using the linear-by-mole fraction blending method, ${ }^{6,30}$ while maintaining the RON close to the chosen base PRF. Last, four-component mixtures were formulated by adding 1-hexene and 1,2,4-trimethylbenzene to the TPRF mixtures, while again maintaining the RON close to the base PRF by changing the iso-octane and $n$-heptane ratios.

In total, 31 different mixtures were formulated, and their RON and MON were measured. The volume percentages and the measured RON, MON, and $\mathrm{S}$ of the various tested mixture are listed in Table 2. Mole percentages for the blends and their measured values are presented in Table S1. The blend number in Table 2 corresponds to the test mixture number in Table S1. The blend ID nomenclature of the different mixtures starts with $\mathrm{LO}$ and $\mathrm{HO}$, in reference to the 70 and $91 \mathrm{RON}$. This is followed by the volume percentages of the added 
Table 2. Mixture Compositions and Respective Measured RON, MON, and Sensitivity

\begin{tabular}{|c|c|c|c|c|c|c|c|c|c|}
\hline \multirow[b]{2}{*}{ blend number ${ }^{a}$} & \multirow[b]{2}{*}{ blend ID } & \multicolumn{5}{|c|}{ volume (\%) } & \multicolumn{3}{|c|}{ measured } \\
\hline & & I-OCT & N-HEP & TOL & 1-HEX & 1,2,4-ТMB & RON & MON & $S$ \\
\hline A10 & PRF91 & 91 & 9 & 0 & 0 & 0 & 91 & 91 & 0 \\
\hline B42 & $\mathrm{HO}-15 \mathrm{~T}$ & 72.5 & 12.5 & 15 & 0 & 0 & 90.5 & 88 & 2.5 \\
\hline B43 & $\mathrm{HO}-30 \mathrm{~T}$ & 52.5 & 17.5 & 30 & 0 & 0 & 89.5 & 84.7 & 4.8 \\
\hline $\mathrm{C} 4$ & $\mathrm{HO}-10 \mathrm{H}$ & 84.69 & 5.1 & 0 & 10.2 & 0 & 92.9 & 90.2 & 2.7 \\
\hline $\mathrm{C} 5$ & $\mathrm{HO}-20 \mathrm{H}$ & 77 & 3 & 0 & 20 & 0 & 93 & 88.5 & 4.5 \\
\hline $\mathrm{C} 14$ & HO-15TMB & 76 & 9 & 0 & 0 & 15 & 94.2 & 90.5 & 3.7 \\
\hline $\mathrm{C} 16$ & НО-30ТМВ & 61 & 9 & 0 & 0 & 30 & 96.8 & 90 & 6.8 \\
\hline C6 & $\mathrm{HO}-15 \mathrm{~T}-10 \mathrm{H}$ & 65 & 10 & 15 & 10 & 0 & 91.2 & 86.8 & 4.4 \\
\hline $\mathrm{C} 8$ & $\mathrm{HO}-15 \mathrm{~T}-20 \mathrm{H}$ & 58 & 7 & 15 & 20 & 0 & 91.7 & 85.2 & 6.5 \\
\hline $\mathrm{C} 10$ & HO-30T-10H & 46.53 & 13.86 & 31.93 & 7.67 & 0 & 91.4 & 84.9 & 6.5 \\
\hline $\mathrm{C} 12$ & HO-30T-20H & 39 & 11 & 30 & 20 & 0 & 90.9 & 82.7 & 8.2 \\
\hline $\mathrm{C} 17$ & HO-8T-7TMB & 75 & 10 & 8 & 0 & 7 & 93.3 & 90.1 & 3.2 \\
\hline $\mathrm{C} 18$ & HO-15T-15TMB & 57.5 & 12.5 & 15 & 0 & 15 & 94.4 & 88.4 & 6 \\
\hline $\mathrm{N} / \mathrm{A}$ & PRF70 & 70 & 30 & 0 & 0 & 0 & 70 & 70 & 0 \\
\hline B40 & $\mathrm{LO}-15 \mathrm{~T}$ & 52 & 33 & 15 & 0 & 0 & 71.2 & 69 & 2.2 \\
\hline B41 & LO-30T & 30 & 40 & 30 & 0 & 0 & 68.4 & 63.7 & 4.7 \\
\hline C19 & $\mathrm{LO}-10 \mathrm{H}$ & 65 & 25 & 0 & 10 & 0 & 74.2 & 72.6 & 1.6 \\
\hline $\mathrm{C} 1$ & $\mathrm{LO}-20 \mathrm{H}$ & 57 & 23 & 0 & 20 & 0 & 74.6 & 72 & 2.6 \\
\hline $\mathrm{C} 7$ & LO-15TMB & 57 & 28 & 0 & 0 & 15 & 77.8 & 74.6 & 3.2 \\
\hline C9 & LO-30TMB & 41 & 29 & 0 & 0 & 30 & 83 & 77.7 & 5.3 \\
\hline $\mathrm{C} 2$ & LO-15T-10H & 44 & 31 & 15 & 10 & 0 & 72 & 68 & 4 \\
\hline $\mathrm{C} 3$ & LO-15T-20H & 36 & 29 & 15 & 20 & 0 & 72 & 67.2 & 4.8 \\
\hline $\mathrm{C} 11$ & LO-8T-7TMB & 54 & 31 & 8 & 0 & 7 & 73.5 & 71.8 & 1.7 \\
\hline $\mathrm{C} 15$ & LO-15T-15TMB & 36 & 34 & 15 & 0 & 15 & 82.6 & 76.2 & 6.4 \\
\hline $\mathrm{C} 13$ & LO-17.65T-12.35TMB & 36 & 34 & 17.65 & 0 & 12.35 & 76.7 & 72 & 4.7 \\
\hline
\end{tabular}

components such as toluene $(\mathrm{T})$, 1-hexene $(\mathrm{H})$, and 1,2,4trimethylbenzene (TMB).

2.2. Ignition Delay Simulations. Zero-dimensional simulations were conducted at a range of temperatures and pressures to find the best correlation between homogeneous gas-phase ignition delay times and the RON and MON of test mixtures. Obtaining this correlation and subsequent analysis of the chemical reactions controlling ignition can give insights into the effects of chemical structure and mixture composition on ignition delay times, as henceforth RON, MON, and S. CHEMKIN-PRO ${ }^{48}$ and CANTERA ${ }^{49}$ on CLOUDFLAME ${ }^{50}$ were used to perform ignition delay calculations for the test mixtures shown in Table S1. These mixtures served as a training set for correlating RON and MON with ignition delay time. The simulations included 11 PRF, 42 TPRF, and 19 MC mixtures. The RON and MON for PRF were given by definition, while those of TPRF and MC were obtained from the literature or measured in this work, as shown in Table 2. The simulations were conducted using the chemical kinetic model proposed by KAUST/LLNL ${ }^{29}$ for gasoline surrogate mixtures, which is capable of simulating low and high temperature ignition delay times for mixtures of $n$-heptane, iso-octane, toluene, 1-hexene, and 1,2,4trimethylbenzene. A complete description of the kinetic model is available in ref 29 .

A constant volume homogeneous batch reactor was used, and the energy equation was solved at a fuel/air equivalence ratio of 1 , which is close to that used in RON and MON tests. Parametric calculations were made across a temperature range of $650-950 \mathrm{~K}$ in increments of $25 \mathrm{~K}$ and a pressure range of $15-50 \mathrm{bar}$ in increments of 5 bar. The temperature and pressure ranges were chosen because previous work ${ }^{25,34}$ has shown that constant volume ignition delay times at these conditions correlate with octane numbers of PRF and TPRF mixtures. Temperatures above $950 \mathrm{~K}$ were not selected for the parametric study because previous work has shown that ignition delay times are largely insensitive to fuel chemistry in the high temperature regime. ${ }^{28,51-55}$ The chosen range of conditions amounts to a total of 6912 simulations for the 72 hydrocarbon mixtures considered herein.
The criterion for ignition delay time was taken as the time corresponding to maximum slope of temperature versus time curve. In case of multiple values for the occurrence of maximum (local) slope, common for fuels with two-stage ignition characteristics, the latest value was chosen as this represents the high temperature (i.e., secondstage) ignition. Simulated ignition delay times were plotted against the mixture's respective RON and MON values, and the initial temperature and pressure conditions giving the best correlation (highest $R$-square value) were chosen.

Once initial temperature and pressure conditions were chosen for the highest $R$-square values, a robust least-square method was used to calculate the best fit to the scatter plot in the form of double exponential curve. This method relies on minimizing the square of the weighted error, calculated as a difference between measured and predicted (i.e., simulated) values. The Levenberg-Marquardt method was used in our analysis to fit the data, which, in essence, is a combination of gradient descent and Gauss-Newton approach. ${ }^{56} \mathrm{~A}$ robust method ensures that outliers do not overinfluence the predicted curves. Our analysis used a bisquare robustness, which iteratively assigns weights on the error, depending on how far the measured value is from the predicted function. ${ }^{57}$

The average (eq 2) and standard errors (eq 3) were calculated for each mixture from the formulas given below and are provided in Table S1.

$$
\begin{aligned}
& \text { average \% error }=\frac{\sum \frac{\text { measured }- \text { predicted }}{\text { measured }}}{n} \times 100 \% \\
& \text { standard error }=\sqrt{\frac{\sum(\text { measured }- \text { predicted })^{2}}{n}}
\end{aligned}
$$

\section{RESULTS AND DISCUSSION}

3.1. Experimental Results. The octane numbers of 25 surrogate mixtures were measured in a CFR engine, and the 


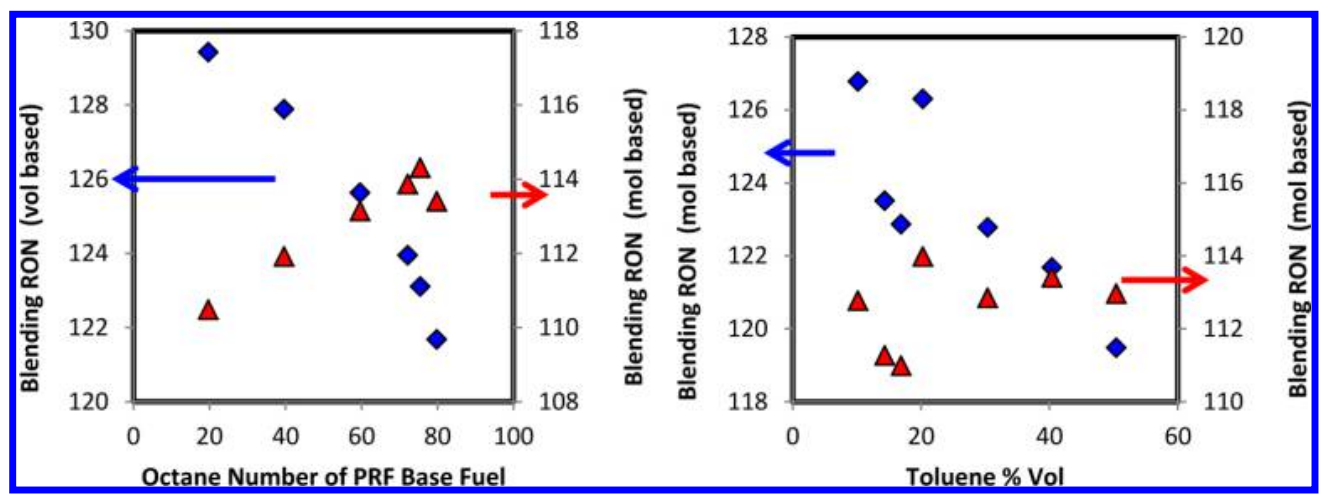

Figure 1. Blending octane numbers of toluene as a function of (a) the PRF base fuel and (b) blending amount in a PRF80. Blue correspond to a linear-by-volume extrapolation (left axis), while red $\boldsymbol{\Delta}$ correspond to a linear-by-mole extrapolation (right axis).

results are reported in Table 2 and Table S1. The measured RON values of the PRF and TPRF mixtures are close to the values estimated using the linear-by-mole method (within the reproducibility limits), as expected on the basis of previous work by Pera and Knop. ${ }^{6}$ However, the measured RON for three-component mixtures containing 1-hexene or 1,2,4trimethylbenzene and four-component mixtures showed larger deviations from the targeted values (70 and 91), indicating that, based on the available literature data, the linear-by-mole method is not suitable for such blends. Nevertheless, as a general trend, the $S$ increases by increasing the percentages of toluene, 1-hexene, and 1,2,4-trimethylbenzene, as expected.

To better assess the blending behavior of toluene, 1-hexene, and 1,2,4-trimethylbenzene, the results are presented in the context of blending octane number. $\mathrm{BON}$ is defined by eqs 4 and 5 .

$$
\begin{aligned}
& C_{\text {base }} \mathrm{RON}_{\text {base }}+C_{i} \mathrm{bRON}_{i}=\mathrm{RON}_{\text {blend }} \\
& C_{\text {base }} \mathrm{MON}_{\text {base }}+C_{i} \mathrm{bMON}_{i}=\mathrm{RON}_{\text {blend }}
\end{aligned}
$$

where $C$ refers to the volumetric concentration of the base fuel or octane additive $i$.

Standard blending RON (bRON) and MON (bMON) are defined on a volume basis and are obtained using a PRF60 as the base fuel. The component of interest is added to the base fuel at a concentration $20 \mathrm{vol} \%$, and then the $\mathrm{RON}_{\text {blend }}$ and $\mathrm{MON}_{\text {blend }}$ of the mixture are measured. The blending RON (bRON) and MON (bMON) are determined through linear extrapolation to the pure component of interest. Although this measure provides useful information about the reactivity of a variety of fuel components when in a mixture, it should be noted that the blending octane number strongly depends on the blending ratio of the base fuel with the component of interest and with the nature of the base fuel. Figure 1a demonstrates how blending toluene at $40 \mathrm{vol} \%$ in different PRFs changes the effective bRON depending on the octane number of the PRF base fuel. The bRON values span a range of 8 units $(\sim 121-129)$. The same plot shows the blending octane numbers of toluene obtained using a linear-by-mole extrapolation. In this case, the blending RON of toluene shows smaller variations spanning a range of 4 units $(\sim 110-114)$. Similarly, Figure 1b, using PRF80 as the base fuel and blending increasing volumes of toluene, shows a decreasing value for the bRON, when using a linear-by-volume blending rule (spanning a range of 7 units). Once again, the scatter obtained via the linear-by-mole rule is limited to only 3 units. This behavior is consistent with that observed by Pera and Knop ${ }^{6}$ and demonstrates why a molar-based blending rule provides more accurate predictions than the volume-based rules. More interestingly, this analysis clearly illustrates why the blending behavior of an unsaturated compound is hardly defined by a single standard tests, and rather depends on the base fuel considered and its blending ratio. Finally, the method used to extract the information can strongly bias the outcome.

If we consider 1,2,4-trimethylbenzene, its tabulated blending RON is 148 when mixed at 20 vol \% with a PRF60. Our results suggest that this value is lower (bRON 140) if mixed in a PRF67, and it is only 121 in a PRF89. The aforementioned values were obtained using a linear-by-volume extrapolation, and, for this compound, shifting to a linear-by-mole extrapolation does not resolve the discrepancy. Similarly, 1hexene's standard bRON in PRF60 is 96, and its bRON in PRF70 and PRF95 is 90 and 80, respectively. The linear-bymole formulation did not present evident advantages over the linear-by-volume method. Similar considerations are valid for their MON values.

On the basis of the data obtained in this work, the blending behavior of 1-hexene and 1,2,4-trimethylbenzene shows a stronger dependence on the base fuel composition as compared to toluene blending behavior. Both the molar-based and the volume-based blending methods are not reliable predictive methods for inferring blending octane numbers for mixtures with 1-hexene and 1,2,4-trimethylbenzene. The uncertainties in measured RON and MON values have a larger impact on their sensitivity values, which is a critical parameter in modern engines. Although empirical nonlinear correlations may be obtained to generate octane number estimates for many fuel components, a fundamental predictive approach to octane blending is still missing.

3.2. Modeling Results. The experimental CFR engine measurements show that a base PRF mixture's RON, MON, and $S$ increase with the addition of various aromatics (toluene and 1,2,4-trimethylbenzene) and olefins (1-hexene). The effect of these components on fuel-air mixture autoignition quality was studied using homogeneous batch reactor simulations with a detailed chemical kinetic model. First, around 7000 simulations were conducted to find the temperature and pressure conditions at which simulated IDT best correlates with measured RON and MON of the various mixtures. For each simulation result, the $(x, y)$ pair of computed ignition delay times and measured octane numbers (RON and MON) were plotted, as shown in Figures 2 and 3.

The analysis revealed that simulated IDT at $T=750 \mathrm{~K}$ and $P$ $=25$ bar provides the best correlation with $\mathrm{RON}$, and $T=825$ 


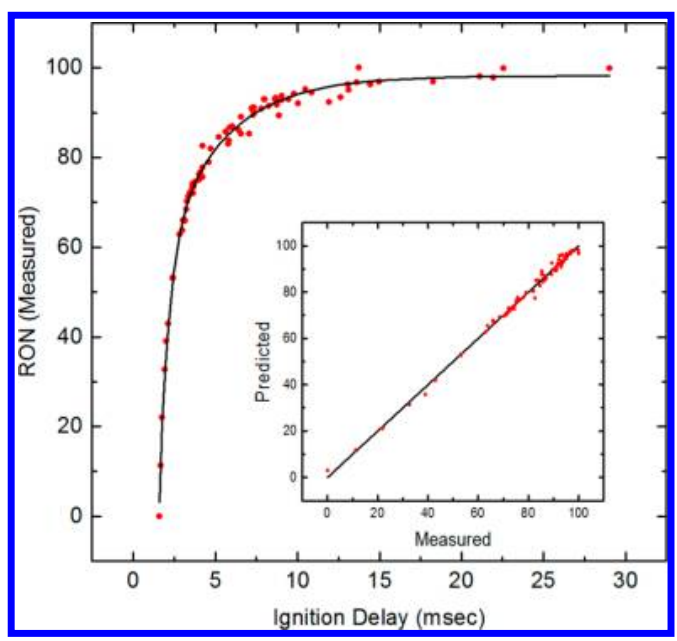

Figure 2. Relationship between measured RON and simulated ignition delay time for various mixtures at $750 \mathrm{~K}$ and 25 bar. Inset shows predicted versus measured RON for all of the tested fuels.

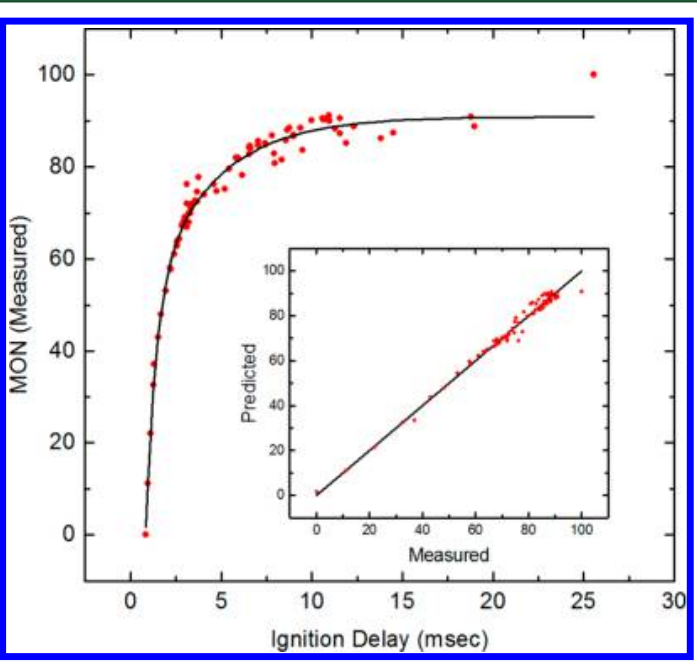

Figure 3. Relationship between measured $\mathrm{MON}$ and simulated ignition delay time for various mixtures at $825 \mathrm{~K}$ and 25 bar. Inset shows predicted versus measured MON for all of the tested fuels.

$\mathrm{K}$ and $P=25$ bar showed the best correlation with MON. Simulated IDT values at other temperatures showed weaker correlations and were thus rejected for further analysis. These values correspond to the typical temperature/pressure condition of the end-gas during knock, rather than experimentally controlled charge inlet temperature. A higher temperature under MON conditions is expected because the knock occurs at a higher end-gas temperature and higher engine speeds. ${ }^{22}$ Previous publications show different temperatures of the endgas corresponding to RON and MON conditions for fuels of varying octane number. Table 3 provides the maximum temperature in case of RON and MON tests found in different studies. A higher octane number translates to a lower tendency to autoignite, so a higher octane fuel achieves a higher maximum end-gas temperature and pressure conditions as compared to a fuel lower octane number fuel. Mittal et al. ${ }^{60}$ suggested an autoignition phenomenon in modern engines takes place at temperatures between 775 and $900 \mathrm{~K}$, while MON tests usually capture the chemical kinetics above $900 \mathrm{~K}$. Overall, these values might be slightly higher than those chosen for our study. It should be noted that the autoignition
Table 3. Maximum Temperatures Found in the Literature Corresponding to RON/MON Tests

\begin{tabular}{|c|c|c|c|c|c|c|}
\hline RON & $T(\mathrm{~K})$ & $P(\mathrm{MPa})$ & MON & $T(\mathrm{~K})$ & $P(\mathrm{MPa})$ & ref \\
\hline 82 & 845 & 3.1 & 73 & 950 & 2.60 & 21 \\
\hline 87 & 851 & 3.24 & 75 & 950 & 2.60 & 21 \\
\hline 90 & 860 & 3.4 & 78 & 951 & 2.60 & 21 \\
\hline 95 & 881 & 3.78 & 80 & 953 & 2.65 & 21 \\
\hline \multirow[t]{3}{*}{100} & 914 & 4.41 & 82.5 & 954 & 2.66 & 21 \\
\hline & & & 85 & 958 & 2.68 & 21 \\
\hline & & & 90 & 974 & 2.93 & 21 \\
\hline 80 & 842 & 3.00 & 82 & 952 & 2.66 & 22 \\
\hline 85 & 850 & 3.17 & 85 & 956 & 2.70 & 22 \\
\hline 90 & 860 & 3.43 & 90 & 973 & 2.90 & 22 \\
\hline 95 & 880 & 3.72 & 95 & 995 & 3.30 & 22 \\
\hline \multirow[t]{7}{*}{100} & 914 & 4.42 & 100 & 1022 & 3.75 & 22 \\
\hline & 800 & 2.3 & & 900 & 2.0 & 58 \\
\hline & & & 86 & 960 & 2.69 & 59 \\
\hline & & & 87 & 964 & 2.77 & 59 \\
\hline & & & 88 & 968 & 2.84 & 59 \\
\hline & & & 89 & 973 & 2.91 & 59 \\
\hline & & & 91 & 980 & 3.00 & 59 \\
\hline
\end{tabular}

chemistry is evolving as the temperature evolves, and the maximum temperatures reported in Table 3 may not be the most relevant parameters to fully understand autoignition chemistry in knocking engines. ${ }^{61}$ For our study, one temperature and pressure were chosen for each of the RON and MON conditions, which enabled a common basis for comparing the underlying chemical kinetic phenomenon driving the reactivity of different fuels.

Plots of simulated IDT versus RON and MON are shown in Figures 2 and 3, respectively. Predicted and measured octane numbers from the curve fit are compared in the inset of each figure. Figure 2 shows calculated IDT values at $750 \mathrm{~K}$ and 25 bar plotted against measured RON. The inset shows the deviation of predicted RON values from those calculated using the function of the curve fit. Using the aforementioned methodology, the curve fit equation for calculating $\mathrm{RON}$ from simulated IDT is given in eq 6 :

$$
\begin{gathered}
\mathrm{RON}=98.21-64.91 \mathrm{e}^{-(\mathrm{IDT} / 0.00363)} \\
-903.7 \mathrm{e}^{-(\mathrm{IDT} / 0.00056)} \\
R^{2}=0.9932
\end{gathered}
$$

Calculated IDT values at $825 \mathrm{~K}$ and 25 bar are plotted against measured MON values in Figure 3. Similar to the previous case, the inset shows little deviation of the measured value from the calculated values. The curve fit provides a similar double exponential function, with different constants, as shown in eq 7 :

$$
\begin{gathered}
\text { MON }=90.96-50.14 \mathrm{e}^{-(\mathrm{IDT} / 0.00361)} \\
-239.6 \mathrm{e}^{-(\mathrm{IDT} / 0.00055)} \\
R^{2}=0.9828
\end{gathered}
$$

The use of a double exponential fit allows very high regression values, as compared to single order response function. The high $R$-square values for both RON and MON equations signify a high level of correlation and fidelity of the proposed model for different multicomponent mixtures. PRF100 (i.e., pure iso-octane) is the only mixture that does not fit well within the MON correlation. This is attributed to the fact that all of the tested mixtures in the training set had 


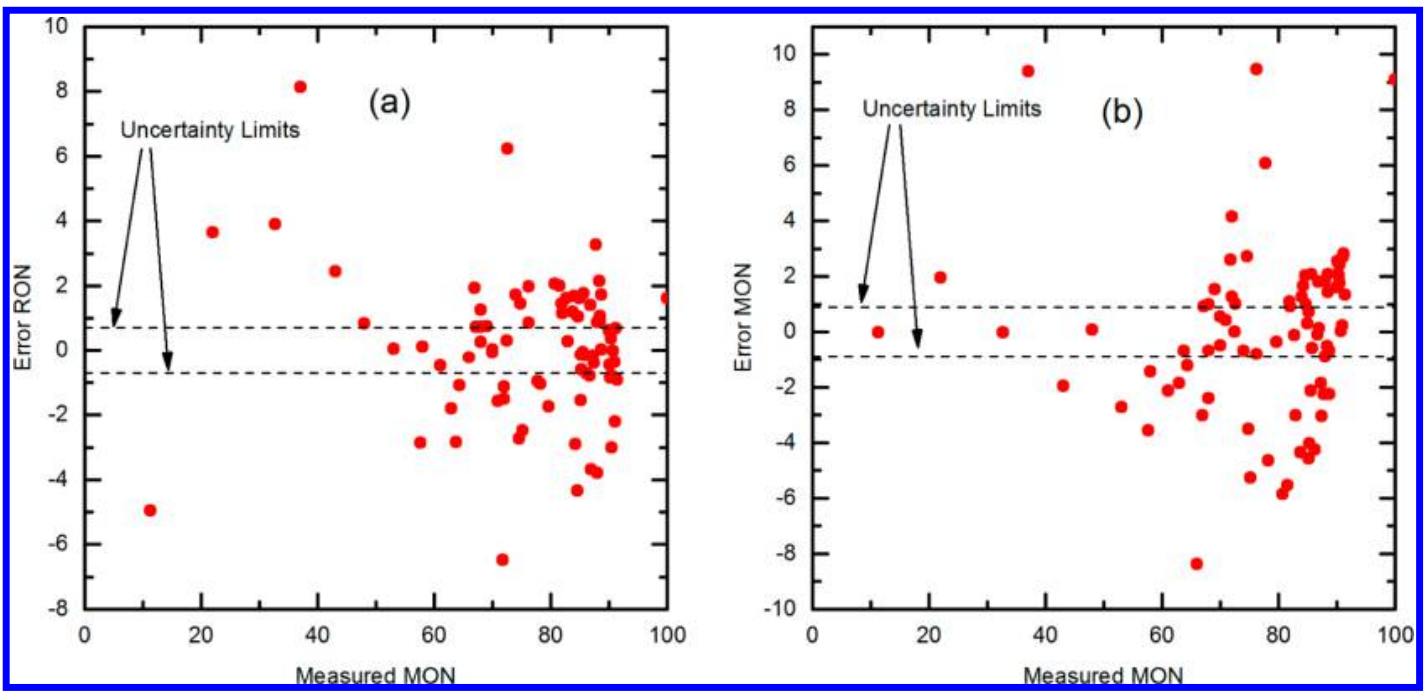

Figure 4. Error in predicted RON (a) and MON (b) and respective uncertainty limits.

MON values near 90 or lower, so the correlation is not suitable for higher MON fuels.

Figure 4 shows the difference in predicted and measured values of RON (Figure 4a) and MON (Figure 4b), in terms of error. The uncertainty limits of the experimental measurements are provided in Figure 4. The repeatability and reproducibility of the RON test are around 0.2 and $0.7 \mathrm{RON}$, respectively. Therefore, any error within $\pm 0.7 \mathrm{RON}$ is within experimental uncertainty. Similar plots (Figure $4 \mathrm{~b}$ ) for error in predicted MON show values bounded within the uncertainty limits. The repeatability and reproducibility of MON measurements are around 0.3 and $0.9 \mathrm{MON}^{6}$ Hence, any error below $\pm 0.9 \mathrm{MON}$ is within experimental uncertainty. Around $30 \%$ of the total predictions are within the limits of experimental uncertainty. Table 4 shows that the majority of the predictions fall within \pm 2 units of measured MON/RON.

\section{Table 4. Error Measurement from the Predicted Values}

\begin{tabular}{lcc} 
& \multicolumn{2}{c}{$\%$ values within bounds } \\
\cline { 2 - 3 } & RON & MON \\
repeatability & 10 & 9 \\
$0.5 \times$ reproducibility & 17 & 15 \\
reproducibility & 27 & 28 \\
\pm 2 ON & 75 & 56 \\
\pm 3 ON & 86 & 77 \\
\hline
\end{tabular}

3.3. Chemical Kinetics Discussion. The previous analysis indicated that IDT values at $T=750 \mathrm{~K}, P=25$ bar and $T=825$ $\mathrm{K}, P=25$ bar show a strong correlation with measured RON and MON values of the tested mixtures. Although the existence of a correlation between the ignition delays at specified conditions and the measured ignition behavior in engine cycles does not necessarily translate into a cause-effect relationship, it should be noted how the differences in the reference temperatures between the data sets for RON and MON correlations are indicative of the differences in temperature obtained in an actual CFR engine for RON and MON measurements. In fact, the MON test involves higher intake temperatures and higher engine speed, resulting in higher endgas temperatures when compared to the RON tests. On the basis of the present statistical analysis, the thermodynamic conditions representative of the RON and MON trends are indeed very close to the trajectories identified in the $T-P$ space for the two engine tests in Mehl et al. ${ }^{24}$ On the basis of this rationale, it is reasonable to conclude that the temperature and pressure conditions used for the correlations are an adequate environment to further investigate the chemistry controlling the ignition process in the RON and MON tests.

A subset of fuel mixtures was selected to investigate the relationship between fuel composition and RON and $S$. As mentioned previously, it is desirable to have fuels with high RON and high $S$, such that their OI is higher in modern engines with negative $K$ values. Thus, simulations of seven fuel mixtures with $\mathrm{RON} \approx 91$ and varying $\mathrm{MON}$ values (hence varying $S$ ) were studied. The mixtures vary in the range from $S$ $=0$ for PRF 91 to $S=11.1$ for a mixture with $23.7 \mathrm{~mol} \% n$ heptane and $76.3 \mathrm{~mol} \%$ toluene. The other five mixtures, with $S$ between 2.5 and 8.2, include one TPRF and four multicomponent mixtures with varying amounts of $n$-heptane, iso-octane, toluene, and 1-hexene.

Previous work by Mehl et al. ${ }^{24}$ has shown that high sensitivity fuels display less negative temperature coefficient (NTC) behavior when compared to fuels with low sensitivity. To investigate this further, we compared the temperature dependence of IDT of the seven selected fuel mixtures. Figure 5 shows the variation of IDT for the seven mixtures at varying temperatures. A modified Bezier curve has been used to interpolate this data. The use of a modified Bezier curve preserves the shape as well as the data points from the calculated values. It is clear that near $750 \mathrm{~K}(1000 / T$ of 1.33$)$, all of the fuels have similar IDT values, which is expected because they have similar RON values; IDT was previously shown to correlate with RON at $750 \mathrm{~K}$. However, the fuels have varying MON values, so their IDT at $825 \mathrm{~K}$ is different. The fuels with low $S$ have high MON, and their IDT at 825 is longer than that for fuels with high $S$ (i.e., low MON). As a general trend, fuels having higher sensitivity display lower reactivity at temperatures below $700 \mathrm{~K}$ and higher reactivity in the NTC region. The highest sensitivity mixture (B18) is anomalous in showing a drastic decrease of reactivity, relative to that of other mixtures considered, at temperatures above $900 \mathrm{~K}$, whereas all of the other fuels appear to converge toward a similar behavior. This unusual behavior is due to the high 


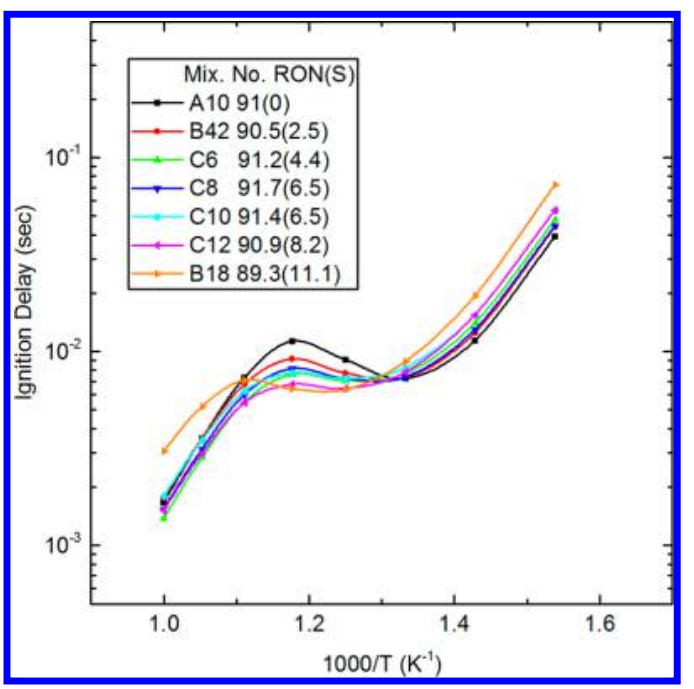

Figure 5. Ignition delay times of similar RON ( 91) and varying sensitivity fuels versus inverse of temperature at 25 bar, stoichiometric fuel/air mixtures. The fuel mixtures are denoted by their mixture number in Table $S 1$ followed by their RON and $S$.

aromatic content of the fuel, which, in this case, is composed only by $n$-heptane and more than $75 \mathrm{~mol} \%$ toluene. The high toluene content not only affects the reactivity in the low temperature region, but also controls the high temperature ignition behavior resulting in significantly different temperature dependence across the window here considered. It should be noted that this mixture is not representative of typical gasoline fuels.

The zero sensitivity PRF 91 shows the most pronounced NTC behavior, and this NTC characteristic decreases as $S$ of the fuel mixture increases. Mixtures C8 (mol \%: $50.15 \mathrm{iC} 8,6.83$ nC7, 20.15 TOL, and 22.86 1-HEX) and C10 (mol \%: 38.17 iC8, $12.83 \mathrm{nC7}, 40.69$ TOL, 8.32 1-HEX) have similar measured RON, MON, and $S$ values despite their varying composition. The simulated IDT values at 25 bar for mixtures C8 and C10, shown in Figure 5, are virtually identical across the entire temperature range, which further supports that the RON and MON values are connected with the intrinsic features of the calculated ignition delay curves obtained using the detailed model.

A major benefit of the homogeneous batch reactor simulations utilized herein is the ability to distinguish chemical kinetic driven ignition reactivity of various fuels under identical temperature, pressure, and equivalence ratio conditions. This makes it possible to attribute any changes in simulated IDT only to the differences in fuel molecular composition. Following previous works, ${ }^{21,62,63}$ we studied the simulated time-histories of temperature, heat release rate (HRR), $\mathrm{OH}$ mole fraction, and $\mathrm{HO}_{2}$ mole fraction. The radical species $\mathrm{OH}$ and $\mathrm{HO}_{2}$ were selected because they are appropriate markers for the radical buildup leading to ignition. ${ }^{64}$ The simulated time histories at RON related conditions (i.e., 25 bar and $750 \mathrm{~K}$ ) and MON related conditions (i.e., 25 bar and $750 \mathrm{~K}$ ) are presented in Figures 6-12 for the seven selected fuel mixtures with RON $\approx 91$ and varying $S$.

At the $750 \mathrm{~K}$ RON-like condition, all of the fuel mixtures display two-stage ignition characteristics. A low temperature heat release (LTHR) peak results in an increase in temperature, which is then followed by a second delay period prior to the main high temperature heat release (HTHR) ignition event. The mole fractions of $\mathrm{OH}$ and $\mathrm{HO}_{2}$ follow the evolution of heat release, showing a distinct local maximum in the LTHR regime. The relationship between low temperature fuel oxidation reactions and first- and second-stage ignition has been discussed extensively in the literature, primarily for paraffinic fuels (i.e., $n$ - and iso-alkanes) ${ }^{65-69}$ Briefly, in the case of paraffins, a series of low temperature radical oxidation $(\mathrm{R}+$ $\mathrm{O}_{2}=\mathrm{RO}_{2}$ ) and subsequent peroxy radical intramolecular isomerization reactions led to the formation of ketohydroperoxides, which decompose to form $\mathrm{OH}$ radicals: a degenerate chain branching sequence $e^{70,71}$ that results in LTHR. The temperature increase $(\sim 75-100 \mathrm{~K})$ following LTHR inhibits the kinetics and thermodynamics of chain branching reactions, and instead favors chain propagation (cyclic ether formation) and chain termination (formation of alkenes and $\mathrm{HO}_{2}$ ) reactions. These competing reactions result in less heat release

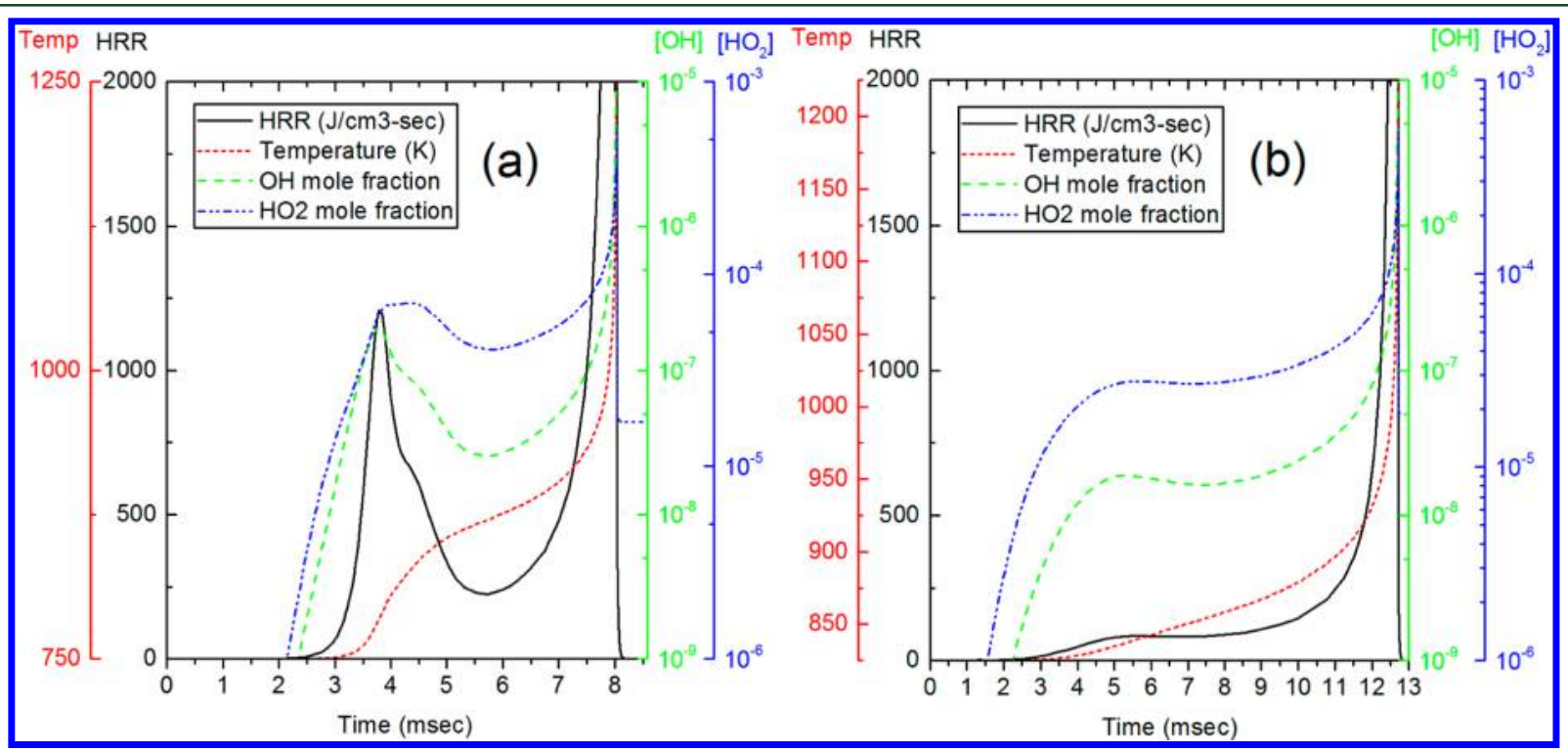

Figure 6. Simulated heat release rate, temperature, and $\mathrm{OH}$ and $\mathrm{HO}_{2}$ mole fractions for the mixture A10, $\mathrm{RON} 91, S 0$, at 25 bar and (a) $750 \mathrm{~K}$, and (b) $825 \mathrm{~K}$. 


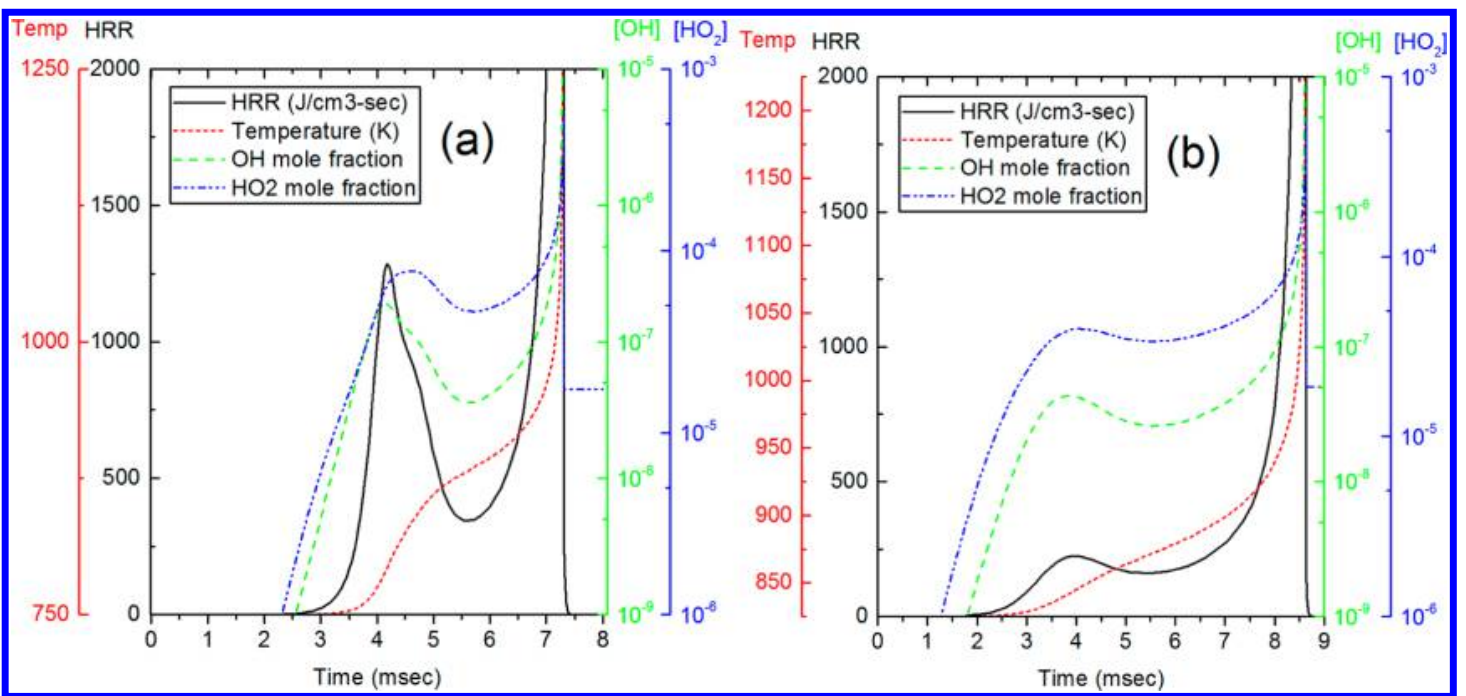

Figure 7. Simulated heat release rate, temperature, and $\mathrm{OH}$ and $\mathrm{HO}_{2}$ mole fractions for the mixture $\mathrm{B} 42$, $\mathrm{RON} 90.5, S 2.5$, at 25 bar and (a) $750 \mathrm{~K}$, and (b) $825 \mathrm{~K}$.

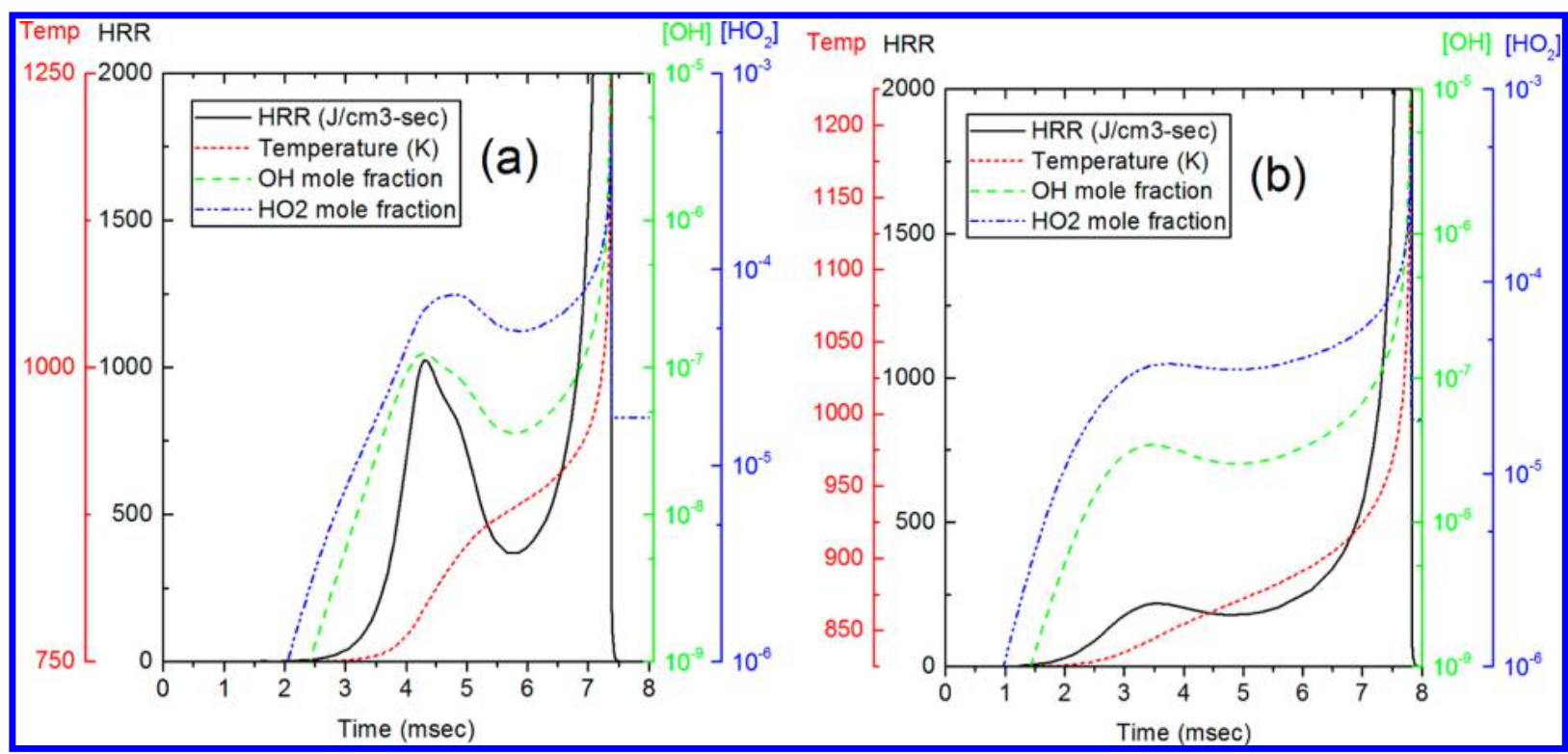

Figure 8. Simulated heat release rate, temperature, and $\mathrm{OH}$ and $\mathrm{HO}_{2}$ mole fractions for the mixture $\mathrm{C} 6, \mathrm{RON} 91.2, S 4.4$, at 25 bar and (a) $750 \mathrm{~K}$, and (b) $825 \mathrm{~K}$.

and thus yield a second ignition delay period. During this second delay period, $\mathrm{HO}_{2}$ radicals abstract hydrogen atoms from the fuel to form $\mathrm{H}_{2} \mathrm{O}_{2}$, which eventually decomposes to 2 $\mathrm{OH}$ radicals and leads to HTHR (i.e., the main ignition event). It is well-known that iso-paraffins (e.g., iso-octane) display less low-temperature reactivity as compared to $n$-paraffins (e.g., $n$ heptane) because the presence of multiple methyl substitutions inhibits the kinetics of low chain branching reactions in isoparaffins. ${ }^{53,67,68}$ The simulation results for PRF91 at $750 \mathrm{~K}$, shown in Figure 6a, clearly display the prominent two-stage ignition characteristic expected for paraffinic mixtures. The production of $\mathrm{OH}$ and $\mathrm{HO}_{2}$ radicals shows a sharp increase up to the LTHR regime.

Figures $7 a-12 a$ show simulation results for mixtures with similar RON but increasing $S$ at $750 \mathrm{~K}$. Note that all mixtures have almost the same total IDT under these conditions, meaning that their HTHR occurs simultaneously. However, it is clear that mixtures with higher $S$ display less LTHR when compared to PRF, such that their first-stage ignition delay periods are longer and the magnitude of the LTHR peak also is also generally reduced.

However, the transition period between LTHR and HTHR during the second-stage ignition delay period is shorter in fuels with higher $S$. The hypothesis was further tested by comparing the second-stage ignition delay period (i.e., the time between LTHR and HTHR) for every mixture in the palette, and an overall agreeable trend of longer second-stage ignition delay period was found with increasing MON, as shown in Figure 13. The analysis indicates that this behavior is associated with a higher reactivity of higher MON fuels in the 850-950 K temperature range.

If we consider the composition of these fuels, the percentage of toluene and 1-hexene increases in fuels with higher $S$, while the paraffinic content decreases. Aromatics and olefins do not display significant low temperature chain branching due to the presence of double bonds and resonantly stabilized radical 


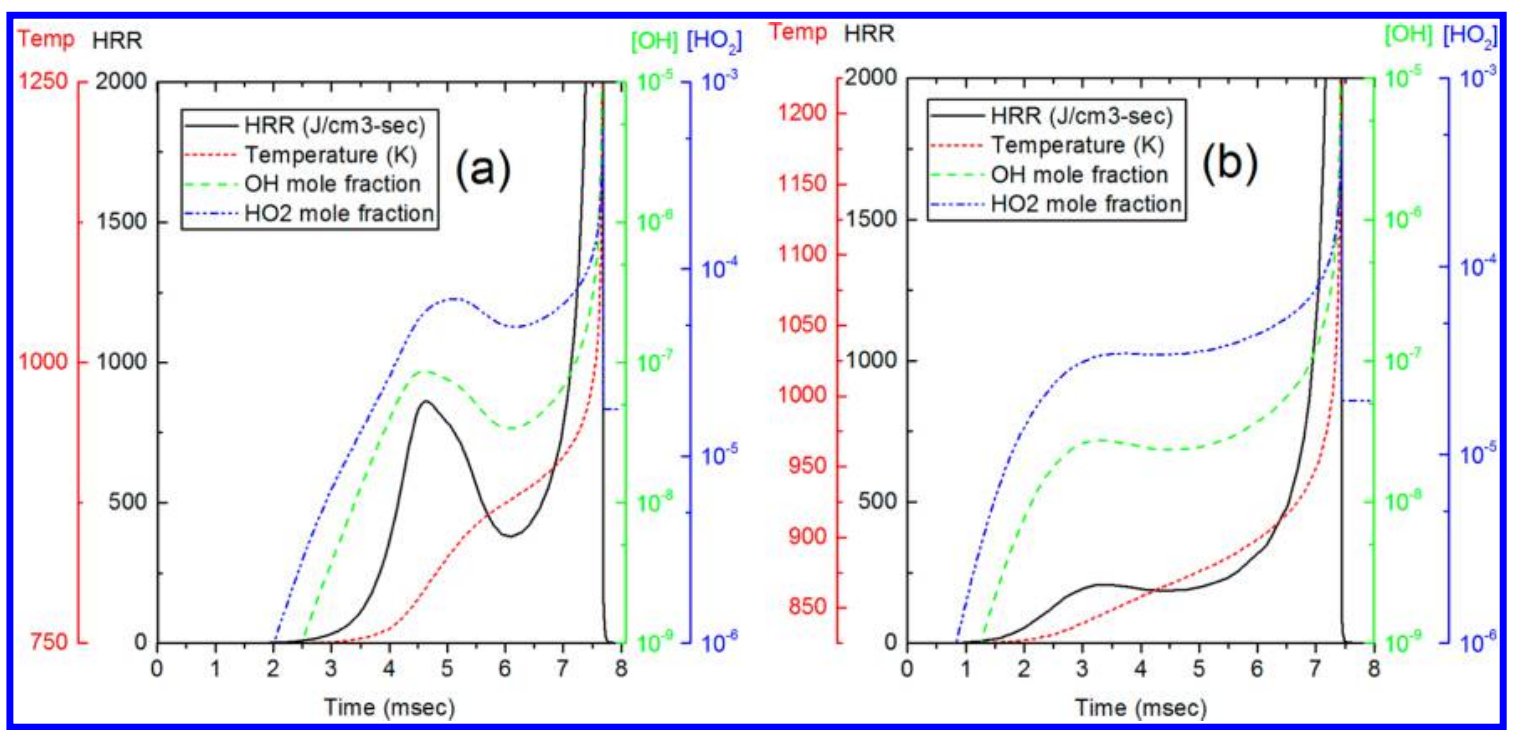

Figure 9. Simulated heat release rate, temperature, and $\mathrm{OH}$ and $\mathrm{HO}_{2}$ mole fractions for the mixture $\mathrm{C} 8$, RON 91.7, $S$ 6.5, at 25 bar and (a) 750 K, and (b) $825 \mathrm{~K}$.
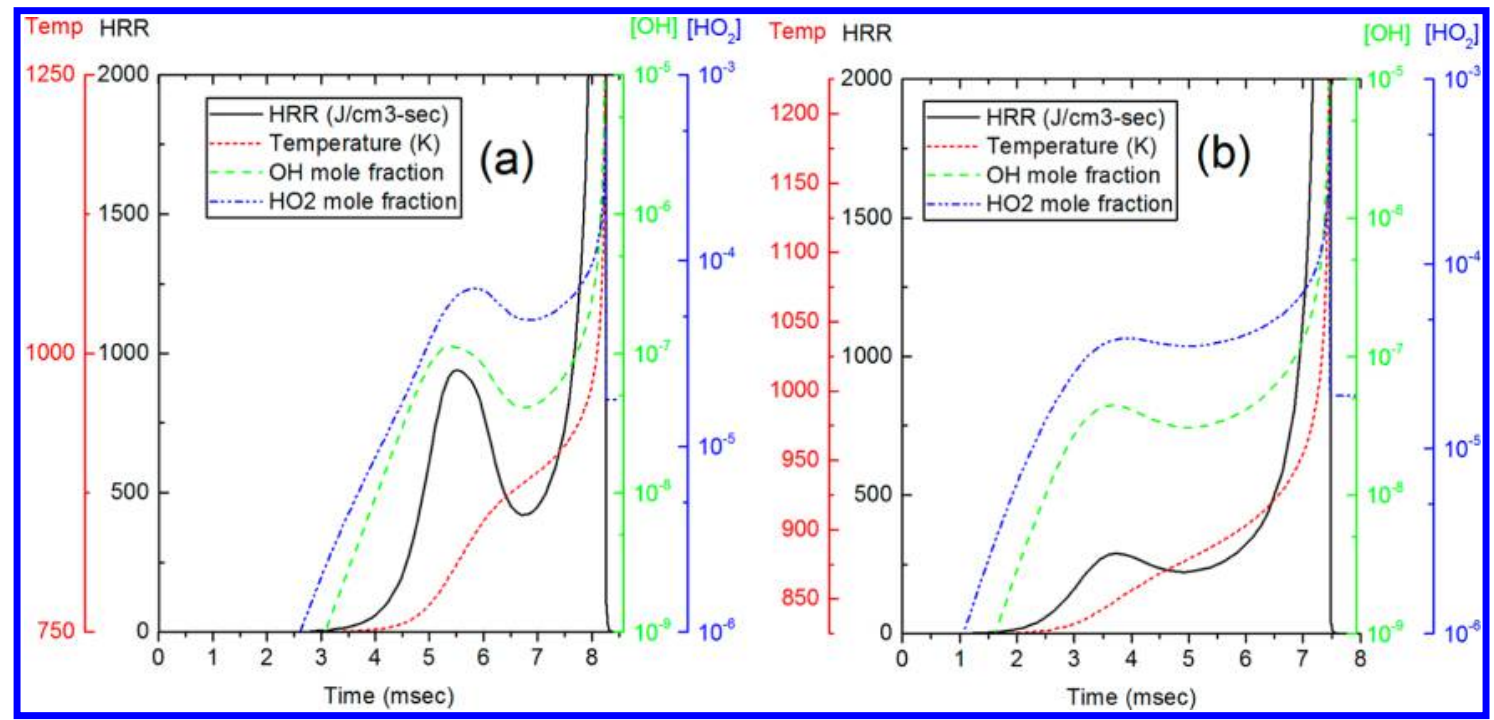

Figure 10. Simulated heat release rate, temperature, and $\mathrm{OH}$ and $\mathrm{HO}_{2}$ mole fractions for the mixture $\mathrm{C} 10$, $\mathrm{RON} 91.4, S 6.5$, at 25 bar and (a) $750 \mathrm{~K}$, and (b) $825 \mathrm{~K}$.

intermediates. $^{72}$ In the case of 1-hexene, low temperature reactivity is governed by chain propagation reactions that produce $\mathrm{OH}$ radicals via the Waddington mechanism; ${ }^{47,73,74}$ chain branching reactions are not favored, and thus 1-hexene leads to a longer first-stage ignition delay period. Alkylaromatics, such as toluene, do not undergo conventional low temperature radical chain branching reactions, and rather act as a sink for $\mathrm{OH}$ radicals due to the easily abstractable benzylic hydrogen atoms. Of the seven mixtures studied at $750 \mathrm{~K}$ and shown in Figures $6 a-12 a$, it is clear that the first-stage ignition delay period becomes longer as the mixture's $S$ increases, and this correlates with a decrease in the paraffinic content and an increase in the olefinic and aromatic content.

Despite the longer first-stage ignition delays in fuels with higher $S$ and higher olefinic and aromatic content, their total ignition delay times are the same as that of purely paraffinic and zero sensitivity PRF91. As explained above, the reactivity of the paraffinic fuels decreases after LTHR because the low temperature degenerate chain branching path is inhibited by the increasing temperature, and therefore the rate of production of $\mathrm{OH}$ radical decreases in favor of propagation reactions leading to $\mathrm{HO}_{2}$ formation. This change in the radical pool composition is responsible for delaying the progression toward high temperature ignition, which happens only when the temperature of the system reaches conditions where the $\mathrm{H}_{2} \mathrm{O}_{2}$ decomposes, reinjecting $\mathrm{OH}$ radicals in the system. On the other hand, fuels with higher olefinic and aromatic content have a shortened second-stage ignition delay period, as shown in Figures $7 a-12 a$. This implies that the temperature rise after LTHR does not inhibit the reactivity of olefins and aromatics, as it does for paraffins. Previous work by Vanhove et al. ${ }^{75}$ has shown that aromatics can increase the reactivity of fuel mixtures at intermediate temperatures (i.e., 800-950 K). The reason for this behavior can be ascribed to the presence of labile benzylic hydrogen atoms, which accelerates abstraction by $\mathrm{HO}_{2}$ radicals, thereby enhancing the formation of $\mathrm{H}_{2} \mathrm{O}_{2}$. In addition, $\mathrm{HO}_{2}$ radicals can undergo bimolecular reaction with benzylic radicals to eventually form benzoxyl radicals and highly reactive $\mathrm{OH}$ 


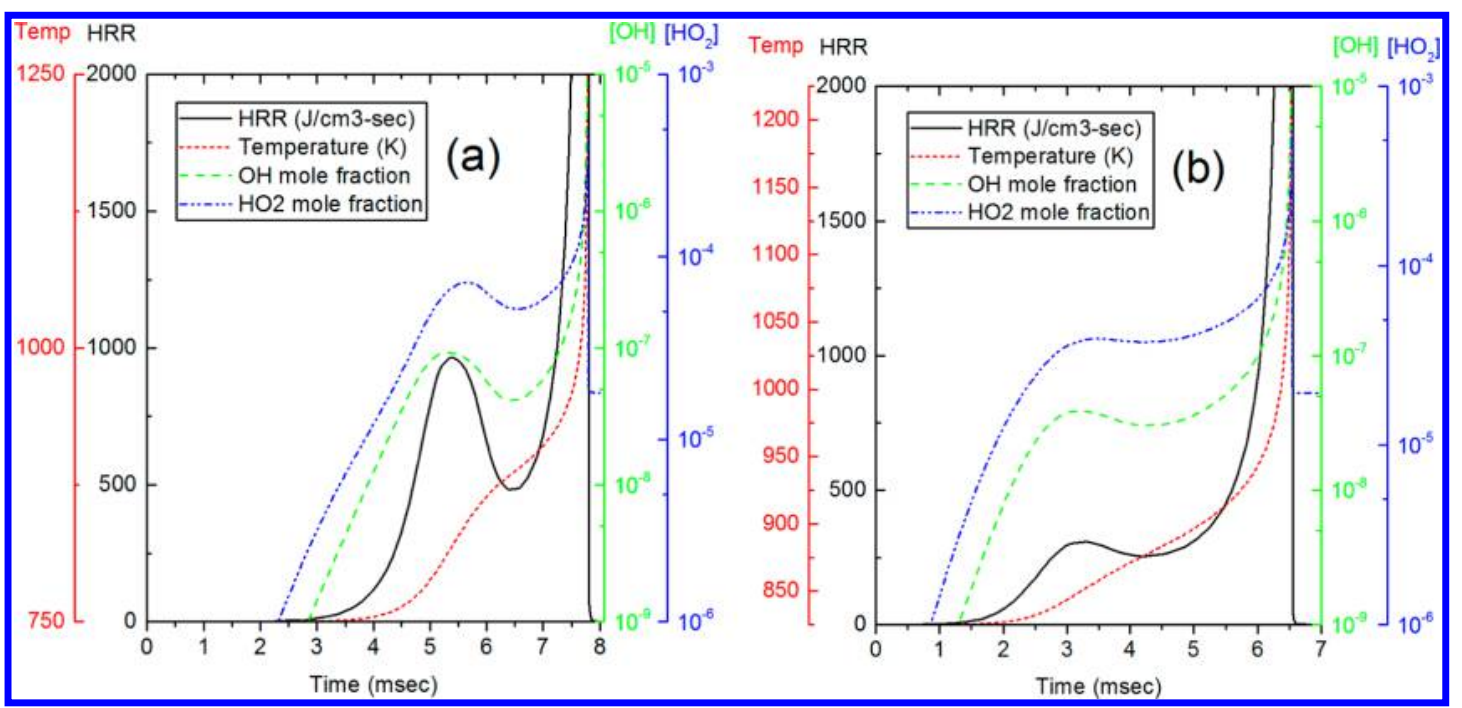

Figure 11. Simulated heat release rate, temperature, and $\mathrm{OH}$ and $\mathrm{HO}_{2}$ mole fractions for the mixture $\mathrm{C} 12$, RON 90.9, $S$ 8.2, at 25 bar and (a) $750 \mathrm{~K}$, and (b) $825 \mathrm{~K}$.

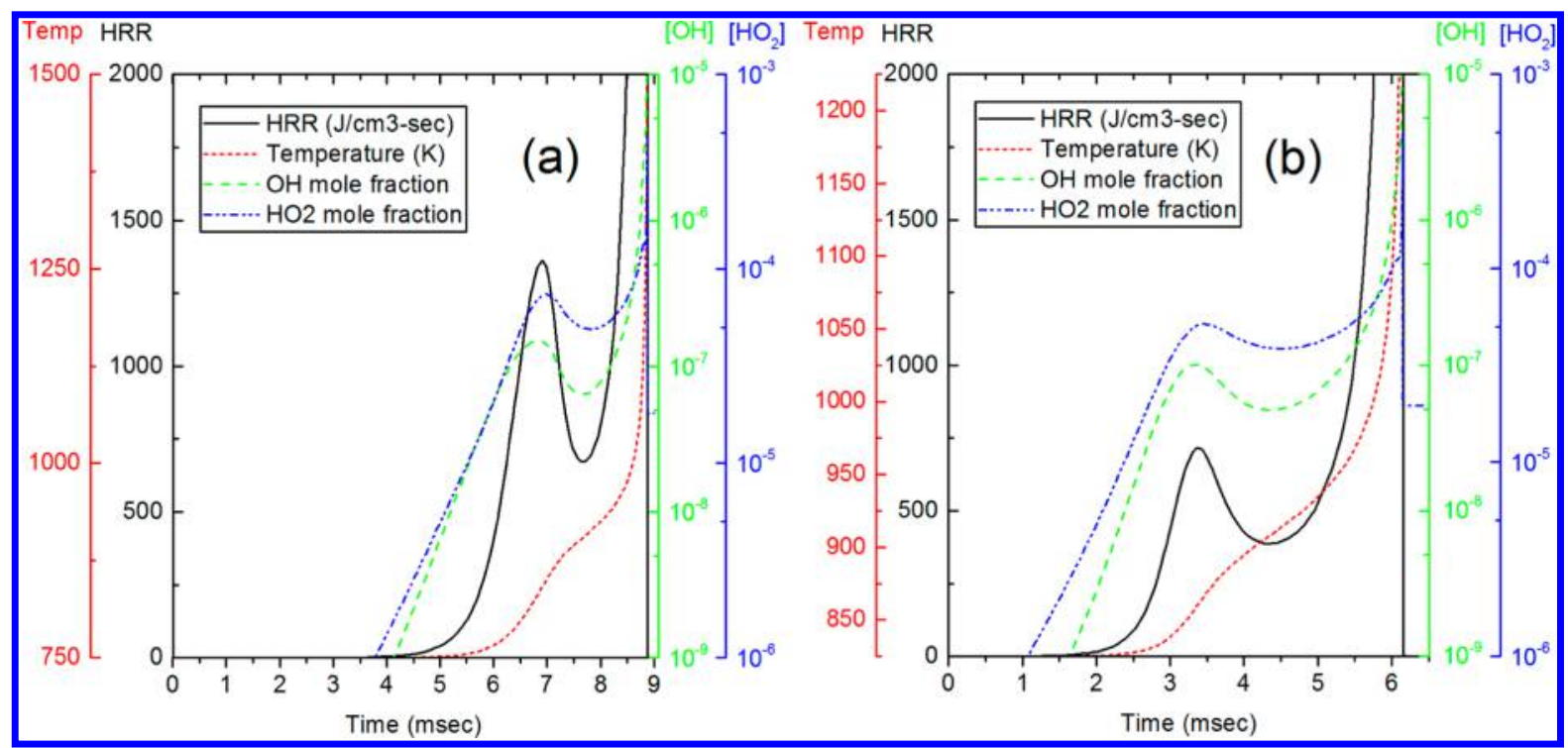

Figure 12. Heat release, temperature, and $\mathrm{OH}$ and $\mathrm{HO}_{2}$ formation near ignition time for the mixture $\mathrm{B} 18, \mathrm{RON} 89.3 .1, S 11.1$, at 25 bar and (a) 750 $\mathrm{K}$, and (b) $825 \mathrm{~K}$.

radicals. ${ }^{76-78}$ Similar chemistry is possible in olefins due to the presence of double bonds and easily abstractable allylic hydrogen atoms. These reactions effectively prevent the concentration of $\mathrm{OH}$ radical from dropping as much as seen in PRFs when coming out of the LTHR stage. In summary, the aforementioned reaction mechanism that is specific to unsaturated hydrocarbons accelerates reactivity at the elevated temperatures following LTHR, and enables mixtures with higher $S$ (i.e., higher olefinic and aromatic content) to display shorter second-stage ignition delay periods. The net result is that the total IDT of all RON91 fuels is the same at 25 bar and $750 \mathrm{~K}$.

Figures $6 \mathrm{~b}-12 \mathrm{~b}$ display time histories of temperature, HRR, and $\mathrm{OH}$ and $\mathrm{HO}_{2}$ radicals at the MON related conditions (825 $\mathrm{K}$ and 25 bar). Recall that the seven test mixtures have similar $\mathrm{RON} \approx 91$ but varying MON (i.e., varying sensitivity). PRF91 in Figure $6 \mathrm{~b}$ has the highest MON and shows the longest ignition delay time, while mixture B18 with the lowest MON (highest $S$ ) displays the shortest IDT. The MON related conditions are in the NTC regime, so fuels with low sensitivity, comprising larger amounts of paraffins, display lower reactivity. At the MON related conditions, the mixtures do not display prominent two-stage ignition characteristics. Instead, a distinguishing feature is a broad intermediate temperature heat release (ITHR) ${ }^{69}$ that transitions to HTHR, causing the main ignition event. For all of the fuel mixtures studied, the magnitude of the ITHR in $825 \mathrm{~K}$ simulations is lower than the magnitude of the LTHR observed in $750 \mathrm{~K}$ simulations. The magnitude of the ITHR also increases as the fuel sensitivity increases, and this is the primary cause of shorter IDT in the low MON fuel mixtures.

The chemical kinetic explanation for lower reactivity of lower sensitivity fuels and higher reactivity of higher sensitivity fuels under the $825 \mathrm{~K} \mathrm{MON}$ related conditions is similar to that previously discussed in the two-stage ignition characteristics observed at $750 \mathrm{~K}$ RON related conditions. The MON related condition is in the NTC regime, and low sensitivity paraffinic fuels are less reactive at these conditions due to the inhibition 


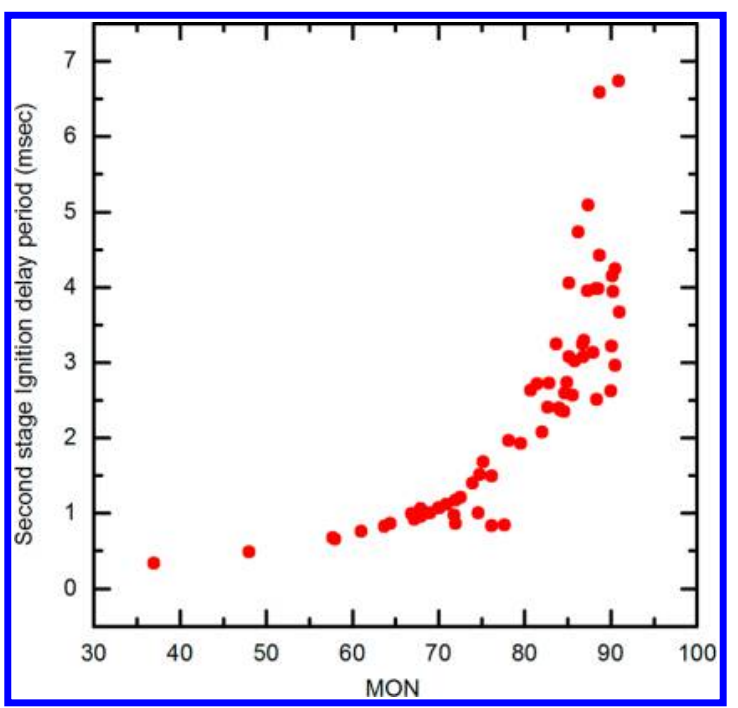

Figure 13. Correlation of measured MON with simulated secondstage ignition delay period (time duration between first-stage ignition (LTHR) and total IDT (HTHR)) for all mixtures at $750 \mathrm{~K}$ and 25 bar.

of low temperature chain branching reactions. On the other hand, high sensitivity fuels contain olefins and aromatics with easily abstractable $\mathrm{H}$ atoms, which facilitate the production of $\mathrm{H}_{2} \mathrm{O}_{2}$, a key intermediate leading to the main ignition. In addition, the benzylic and allylic radicals can react with $\mathrm{HO}_{2}$, which eventually leads to the formation of $\mathrm{OH}$, thereby accelerating ignition, as discussed previously.

A recent paper by Kalghatgi ${ }^{79}$ showed that PRF fuels are comparably less resistant to autoignition as pressure increases for a given temperature when compared to non-PRF fuels (or, in other words, fuels containing components exhibiting octane sensitivity). This results in non-PRF fuels having higher OI at conditions relevant to modern engines. To further understand the role of fuel composition on sensitivity, simulations were analyzed to understand how increasing pressure affects IDT. The effect of pressure on IDT is given in Figure 14, wherein the $7 \mathrm{RON} \approx 91$ test mixtures are compared at $825 \mathrm{~K}$. At these conditions, fuels with higher sensitivity are more reactive than fuels with lower sensitivity (we previously discussed how their

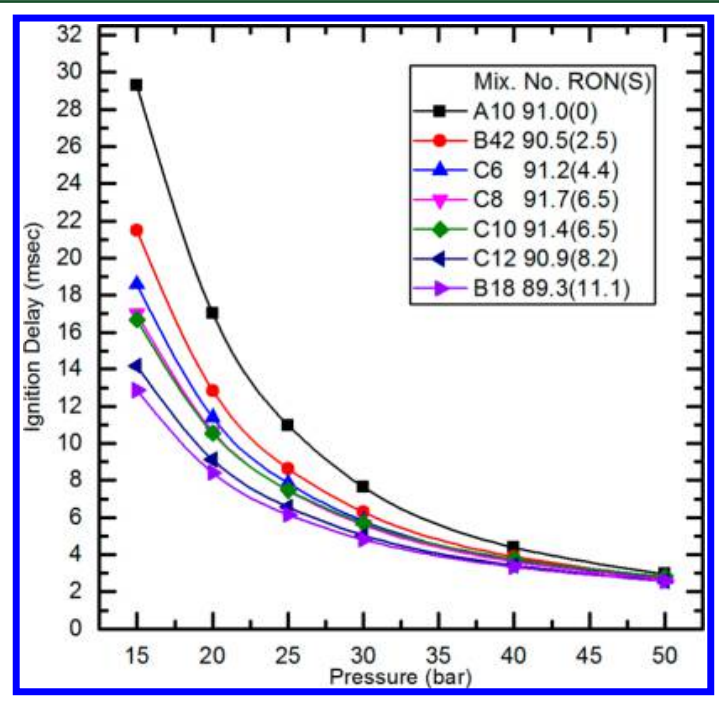

Figure 14. Variation of ignition delay time as a function of pressure for fuels with similar RON values and varying sensitivity at $825 \mathrm{~K}$.
MON correlates with the ignition delay at $825 \mathrm{~K}$ ). It should be noticed that the same plot obtained at a different temperature can look drastically different (e.g., at $650 \mathrm{~K}$ the relative reactivity of low sensitivity RON91 fuels is greater than that of high sensitivity fuels), but here we chose to focus on the NTC region because it is the typical temperature range where knock is observed in engines.

The results show a decreasing curvature with increasing values of sensitivity. This is reflected by the monotonically decreasing value of pressure exponent in Table 5 and discussed below. The monotonic reduction warrants the use of a spline function to interpolate the calculations.

Figure 14 shows that as pressure increases the IDT decreases, especially at lower pressures. At pressures above 45 bar, the IDT values of all mixtures converge. It can be seen that, at 50 bar, the ignition delay values of all of the fuels are, more or less, the same. This is due to a disparate response of the fuels of varying sensitivity to change in pressure, which is explained now. Considering the effect of sensitivity, mixture A10 (PRF91) with zero sensitivity displays a prominent decrease in IDT with increasing pressure, while fuels with higher sensitivity show comparably less change in IDT as pressure increases. Of particular interest are mixtures C8 (mol \%: 50.15 iC8, $6.83 \mathrm{nC7}, 20.15 \mathrm{TOL}$, and 22.86 1-HEX) and C10 (mol \%: 38.17 iC8, 12.83 nC7, 40.69 TOL, 8.32 1-HEX), which have similar RON and MON (and hence similar $S$ ) values but different compositions. The overlapping IDT for these mixtures across a range of temperature conditions has been mentioned previously. The statement can further be extended here to a range of pressure conditions, as we observe complete overlap of the two curves for C8 and C10. IDT simulations at $750 \mathrm{~K}$ (not shown) for pressures ranging from 15 to 50 bar are within a range of $2 \mathrm{~ms}$ for all seven mixtures, which conforms well to the RON values (25 bar) and extends further to other pressures as well. This further points to the fidelity of the model used for simulations to match experimental observations. In summary, Figure 14 indicates that for high sensitivity fuel mixtures with large aromatic/olefin content, the tendency to autoignition is growing to a lesser extent than is the case for low sensitivity fuels with higher paraffin content.

Using a least-square method for curve fitting, ignition delay follows a simple function with pressure as given by eq 8 :

$$
\mathrm{IDT}=a P^{-n}
$$

Values of constants $a$ and $n$ of this expression, along with $R$ square value, are given in Table 5 .

Similar relations, with very good correlation ( $R$-square nearly 1) were also found for all 79 mixtures (not shown in the interest of space). The pressure dependence of IDT is then simply given by the factor $n$ term in the equation. The values of pressure dependence factor $n$ were then plotted against the (measured) sensitivity of each mixture, as shown in Figure 15. The scatter shows a trend, which can be represented by a linear relation (eq 9) with a negative slope.

$$
n=-0.0419 S+1.822
$$

The $R$-square value of 0.8476 for the above relation is a testament to the linear correlation.

The dependence of IDT on pressure is well-known in the literature. However, a direct correlation between pressure dependence and sensitivity is presented here for the first time, and the curvature (given by the pressure exponent) is found to decrease linearly with sensitivity. Again, the existence of a 
Table 5. Constants " $a$ " and " $n$ " and $R^{2}$ Value for Fuels of RON $\approx 91$ and Varying Sensitivities

\begin{tabular}{|c|c|c|c|c|c|c|c|}
\hline & \multicolumn{7}{|c|}{ mixture no. } \\
\hline & A10 & B42 & C6 & $\mathrm{C} 8$ & $\mathrm{C} 10$ & $\mathrm{C} 12$ & B18 \\
\hline $\operatorname{RON}(S)$ & $91(0)$ & $90.5(2.5)$ & $91.2(4.4)$ & $91.7(6.5)$ & $91.4(6.5)$ & $90.9(8.2)$ & $89.3(11.1)$ \\
\hline$a$ & 5.2691 & 2.1507 & 1.4407 & 1.0898 & 0.9034 & 0.643 & 0.4632 \\
\hline$n$ & 1.918 & 1.709 & 1.615 & 1.544 & 1.484 & 1.419 & 1.335 \\
\hline$R^{2}$ & 0.9998 & 0.9993 & 0.9992 & 0.9992 & 0.9989 & 0.9987 & 0.9981 \\
\hline
\end{tabular}

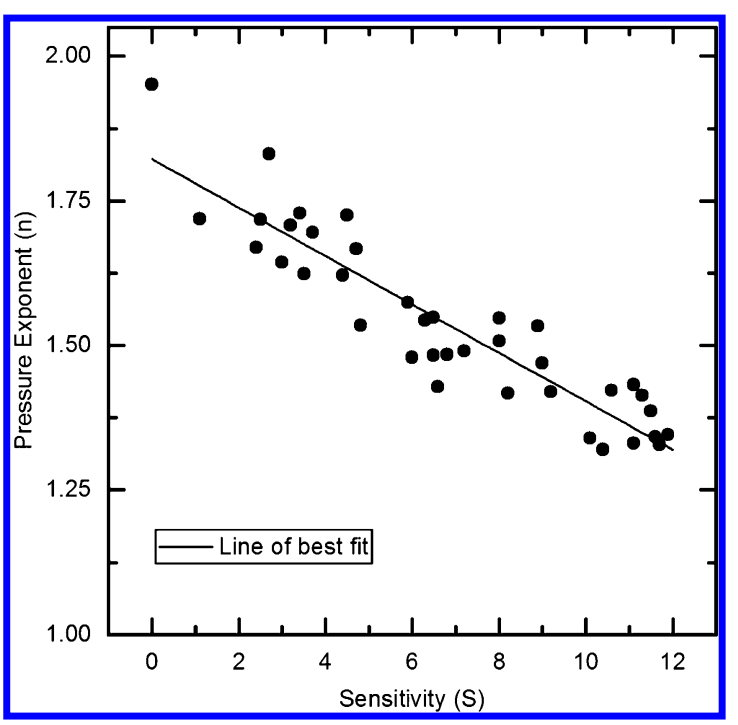

Figure 15. Predicted relationship between pressure dependence, as denoted by pressure exponent ( $y$-axis), and fuel sensitivity at $825 \mathrm{~K}$ and 25 bar for all fuels with RON greater than 90 .

statistical correlation between pressure dependence and sensitivity does not imply a cause-effect relationship. Ignition delay times of fuels have a stronger dependence on temperature than on pressure. The former typically follows an exponential Arrhenius-type relationship, except in the NTC region. The dependence of ignition on pressures follows a power law relationship with exponents in the range of $1-3$. The temperature differences observed in the RON versus MON cycle are more important factors in determining the ignition timing as compared to the effect of pressure changes. The chemical kinetic explanation for the link between pressure exponent and sensitivity again lies in the mixture composition and its implications on the low temperature reactivity. As shown previously, mixtures with low sensitivity contain primarily paraffinic components that display prominent low temperature chemistry. The distinguishing feature of this low temperature chemistry is the bimolecular reaction of fuel radicals $(\mathrm{R})$ with molecular oxygen $\left(\mathrm{O}_{2}\right)$ to form alkylperoxy radicals, as well as the second $\mathrm{O}_{2}$ addition to alkylhydroperoxy radicals. These bimolecular reactions become faster as pressure increases due to the higher concentration of radicals and oxygen, which results in a significant decrease in IDT for paraffinic low sensitivity fuels. On the other hand, the same low temperature chemical reaction pathways do not govern the reactivity of fuels with high sensitivity comprising olefins and aromatics. These fuels do not display prominent low temperature chemistry and primarily act as a sink for $\mathrm{OH}$ radicals. As pressure increases, more fuel radicals are produced, but the subsequent reactivity of these radicals is not strongly dependent on $\mathrm{O}_{2}$ concentration, and therefore IDT of higher sensitivity fuel mixtures is not strongly affected by increasing pressure.
The effectiveness of this low temperature mechanism defines both the temperature and the pressure dependences of the IDT and, therefore, the knock properties of the fuel: prominent low temperature reactivity results in high pressure exponent and reduced temperature dependence due to NTC behavior. On the other hand, unsaturated compounds limit the effectiveness of the low temperature oxidation processes due to kinetically unfavorable chain branching reactions, ${ }^{72}$ low activation energy propagation pathways (e.g., addition of $\mathrm{OH}$ and $\mathrm{HO}_{2}$ on the double bond), and radical scavenging when present in mixtures. As a result, these fuels show stronger temperature dependence (which results in a larger difference between their RON and MON values) and weaker pressure effects, both of which benefit engine operations at the low temperatures achieved in modern engines.

\section{CONCLUSION}

This study provided new insights into the effects of fuel composition on RON, MON, and $S$, which are all important parameters for characterizing the antiknock quality of gasoline fuels. Modern engines using fuels with higher RON and high $S$ can achieve higher efficiency. Experimental measurements of surrogate fuel mixtures in a CFR engine showed that addition of various aromatics (toluene and 1,2,4-trimethylbenzene) and olefins (1-hexene) increases the RON and $S$ of a base PRF mixture. The blending octane values of toluene, 1-hexene, and 1,2,4-trimethylbenzene have been investigated for a variety of blending levels and base fuel compositions. This analysis showed how the estimates of the antiknock behavior of different compounds in mixtures can change significantly depending on the mixture composition and the methods used to extrapolate their octane numbers. These findings clearly demonstrate how a predictive approach to octane behavior is challenging to achieve.

To provide chemical kinetic insights on the role of surrogate fuel composition on octane quality, simulated 0-D ignition delay times were correlated with measured RON and MON of 79 mixtures. This work advanced previous correlations in the literature by including additional molecules into the mixture, such as 1,2,4-trimethylbenzene and 1-hexene. The models developed show a high level of correlation with experimental measurements. Similar RON fuels were studied further to understand the effects of fuel composition on octane sensitivity. Under two-stage ignition conditions, higher octane sensitivity (high RON and low MON) fuels showed later first-stage ignition delay times, lower LTHR, and a shorter second-stage ignition delay period. Under single stage ignition conditions, ITHR was found to increase with increasing fuel octane sensitivity.

Low sensitivity fuels are primarily paraffinic in nature, and thus display a large amount of LTHR followed by NTC behavior. Chemical kinetic modeling and analysis of $\mathrm{OH}$ and $\mathrm{HO}_{2}$ radical concentration profiles showed that low temperature radical chain branching reactions lead to rapid formation 
of $\mathrm{OH}$ radicals in paraffinic fuels at low temperatures, but propagation reactions decrease the activity of the radical pool in the NTC regime. Higher sensitivity fuels comprising olefins and aromatics display less LTHR, but lack NTC behavior, thereby causing them to be more reactive at intermediate temperatures. At low temperatures, olefins and aromatics are unable to populate the radical pool due to lack of low temperature chemistry. When in mixtures, these compounds scavenge radicals that would otherwise promote LTHR; however, as temperature increases, reactions specific to unsaturated hydrocarbons interfere with NTC behavior and enable radical pool production.

This study also demonstrated that higher sensitivity fuels become less prone to autoignition as pressure increases when compared to lower sensitivity fuels. It was found that the pressure exponent decreases with increasing fuel octane sensitivity. When examined for all high RON fuels, a good correlation was found between the two aforementioned parameters. Again, the effects of pressure on autoignition propensity were elucidated by chemical kinetic modeling of the various mixtures. Low sensitivity fuels with high paraffinic content become comparably more prone to autoignition as pressure increases due to the bimolecular nature of low temperature chain branching oxidation reactions.

In summary, this article demonstrates that chemical kinetic modeling can be used to understand the relationships between gasoline fuel composition and antiknock quality (i.e., octane number and sensitivity). The simple correlations presented herein can be used to screen various fuel mixtures for desired RON, MON, and $S$. This enables a novel approach of simulation-driven fuel design, significantly reducing the need for expensive and time-consuming experiments, and providing new opportunities for improving the efficiency of gasoline spark ignition engines.

\section{ASSOCIATED CONTENT}

\section{S Supporting Information}

The Supporting Information is available free of charge on the ACS Publications website at DOI: 10.1021/acs.energyfuels.6b02659.

Tested mixtures, and measured and predicted RON, $\mathrm{MON}$, and $S$ (PDF)

\section{AUTHOR INFORMATION}

\section{Corresponding Authors}

*E-mail: eshan.singh@kaust.edu.sa.

*Tel.: +966 (0) 544700142. E-mail: mani.sarathy@kaust.edu.sa. ORCID

Eshan Singh: 0000-0001-8851-4724

Notes

The authors declare no competing financial interest.

\section{ACKNOWLEDGMENTS}

This work was supported by the Saudi Aramco R\&DC and Clean Combustion Research Center at King Abdullah University of Science and Technology (KAUST) under the FUELCOM Research Program. We are thankful for Sherif Khalifa's contribution to this project during his internship sponsored by the KAUST Visiting Student Research Program (VSRP). The work at LLNL was supported by the U.S. Department of Energy, Vehicle Technologies Office, program managers Gurpreet Singh and Leo Breton and was performed under the auspices of the U.S. Department of Energy by Lawrence Livermore National Laboratories under contract DEAC52-07NA27344

\section{REFERENCES}

(1) Kalghatgi, G. Outlook for fuels in internal combustion engines. Int. I. Engine Res. 2014, 15, 383.

(2) Heywood, J. B. Internal Combustion Engine Fundamentals; McGraw Hill Book Co.: New York, 1988.

(3) Kalghatgi, G. T. Fuel/Engine Interactions; SAE International: Warrendale, PA, 2014; Chapter 4.

(4) Kalghatgi, G.; Morganti, K.; Algunaibet, I.; Sarathy, M.; et al. Knock Prediction Using a Simple Model for Ignition Delay. SAE Technical Paper 2016-01-0702, 2016, doi: 10.4271/2016-01-0702.

(5) Spicher, U.; Kröger, H.; Ganser, J. Detection of knocking combustion using simultaneously high-speed schlieren cinematography and multi optical fiber technique, 1991.

(6) Knop, V.; Loos, M.; Pera, C.; Jeuland, N. A linear-by-mole blending rule for octane numbers of n-heptane/iso-octane/toluene mixtures. Fuel 2014, 115 (C), 666-673.

(7) ASTM D2700-16. Standard Test Method for Motor Octane Number of Spark-Ignition Engine Fuel; ASTM International: West Conshohocken, PA, 2016.

(8) Edgar, G. Measurement of Knock Characteristics of Gasoline in Terms of a Standard Fuel. Ind. Eng. Chem. 1927, 19, 145.

(9) ASTM D2699-12. Standard Test Method for Research Octane Number of Spark-Ignition Engine Fuel; ASTM International: West Conshohocken, PA, 2012.

(10) Mittal, V.; Heywood, J. The Shift in Relevance of Fuel RON and MON to Knock Onset in Modern SI Engines Over the Last 70 Years. SAE Int. I. Engines 2010, 2 (2), 1-10.

(11) Burluka, A.; Liu, K.; Sheppard, C.; Smallbone, A.; et al. The Influence of Simulated Residual and NO Concentrations on Knock Onset for PRFs and Gasolines. SAE Technical Paper 2004-01-2998, 2004; doi: 10.4271/2004-01-2998.

(12) Foong, Tien Mun; Brear, Michael J.; Morganti, Kai J.; Gabriel da, Silva; Yi, Yang; Frederick, L. Dryer. Modelling end-gas autoignition of ethanol/gasoline surrogate blends in the CFR engine. Energy Fuels 2016, 1 DOI: 10.1021/acs.energyfuels.6b02380.

(13) Foong, T. M.; Morganti, K. J.; Brear, M. J.; da Silva, G.; Yang, Y.; Dryer, F. L. The effect of charge cooling on the RON of ethanol/ gasoline blends. SAE International Journal of Fuels and Lubricants 6 2013, 6, 34-43.

(14) Kasseris, E.; Heywood, J. B. Charge cooling effects on knock limits in SI DI engines using gasoline/ethanol blends: Part 1quantifying charge cooling. No. 2012-01-1275, SAE Technical Paper, 2012.

(15) Kasseris, Emmanuel; Heywood, John B. Charge cooling effects on knock limits in SIDI engines using gasoline/ethanol blends: part 2effective octane numbers. SAE International Journal of Fuels and Lubricants 5 2012, 5, 844-854.

(16) Kalghatgi, G. T. Auto-ignition quality of practical fuels and implications for fuel requirements of future SI and HCCI engines. SAE Paper 2005-01-0239, 2005.

(17) Kalghatgi, G. T. Fuel Anti-knock Quality - Part I, Engine studies. SAE Paper 2001-01-3584, 2001.

(18) Kalghatgi, G. T. Fuel anti-knock - Part II., Vehicle studies- how relevant is Motor Octane Number (MON) for modern engines? SAE Paper 2001-01-3585, 2001.

(19) Westbrook, C. K.; Mehl, M.; Pitz, W. J.; Sjöberg, M. Chemical kinetics of octane sensitivity in a spark-ignition engine. Combust. Flame 2017, 175, 2-15.

(20) Hudgens, I. W. Workshop on Combustion Simulation Databases for Real Transportation Fuels; NIST: Gaithersburg, MD, 2003.

(21) Daly, Shane R.; Niemeyer, Kyle E.; Cannella, William J.; Christopher, L. Hagen. Predicting fuel research octane number using 
Fourier-transform infrared absorption spectra of neat hydrocarbons. Fuel 2016, 183, 359-365.

(22) Abdul Jameel, A. G.; Naser, N.; Emwas, A.-H.; Dooley, S.; Sarathy, S. M. Predicting Fuel Ignition Quality Using $1 \mathrm{H}$ NMR Spectroscopy and Multiple Linear Regression. Energy Fuels 2016, 30, 9819-9835.

(23) Lovell, Wheeler G. Knocking characteristics of hydrocarbons. Ind. Eng. Chem. 1948, 40 (no. 12), 2388-2438.

(24) AlRamadan, Abdullah S.; Sarathy, S. Mani; Khurshid, Muneeb; Jihad, Badra. A blending rule for octane numbers of PRFs and TPRFs with ethanol. Fuel 2016, 180, 175-186.

(25) Ghosh, P.; Hickey, K. J.; Jaffe, S. B. Development of a detailed gasoline composition-based octane model. Ind. Eng. Chem. Res. 2006, 45 (1), 337-345

(26) Nikolaou, N.; Papadopoulos, C. E.; Gaglias, I. A.; Pitarakis, K. G. A new non-linear calculation method of isomerisation gasoline research octane number based on gas chromatographic data. Fuel 2004, 83 (no. 4), 517-523.

(27) Protić-Lovasić, Gorana; Jambrec, Nada; Deur-Siftar, Djurdja; Mladen, V. Prostenik. Determination of catalytic reformed gasoline octane number by high resolution gas chromatography. Fuel 1990, 69 (no. 4), 525-528.

(28) Lugo, Heli J.; Giuseppina, Ragone; Jose, Zambrano. Correlations between octane numbers and catalytic cracking naphtha composition. Ind. Eng. Chem. Res. 1999, 38 (no. 5), 2171-2176.

(29) Durand, J. P.; Boscher, Y.; Dorbon, M. On-line chromatographic analyser for determining the composition and octane number of reforming process effluents. Iournal of Chromatographv A 1990, 509 (no. 1), 47-51.

(30) Pera, C.; Knop, V. Methodology to define gasoline surrogates dedicated to auto-ignition in engines. Fuel 2012, 96, 59.

(31) Bradley, D.; Head, R. A. Engine autoignition: The relationship between octane numbers and autoignition delay times. Combust. Flame 2006, 147, 171.

(32) Leppard, W. R. The chemical origin of fuel octane sensitivity. SAE technical paper 90-21-37, 1990.

(33) Thirouard, B.; Cherel, J.; Knop, V. Investigation of mixture quality effect on CAI combustion. SAE technical paper 2005-01-0141, 2005.

(34) Mehl, M.; Pitz, W. J.; Westbrook, C. K.; Curran, H. J. Kinetic modeling of gasoline surrogate components and mixtures under engine conditions. Proc. Combust. Inst. 2011, 33, 193-200.

(35) Mehl, M.; Chen, J. Y.; Pitz, W. J.; Sarathy, S. M.; Westbrook, C. $\mathrm{K}$. An approach for formulating surrogates for gasoline with application toward a reduced surrogate mechanism for CFD engine modeling. Energy Fuels 2011, 25 (11), 5215-5223.

(36) Perez, P. L.; Boehman, A. L. Experimental investigation of the autoignition behavior of surrogate gasoline fuels in a constant-volume combustion bomb apparatus and its relevance to HCCI combustion. Energy Fuels 2012, 26, 6106-17.

(37) Sarathy, S. M.; Kukkadapu, G.; Mehl, M.; Wang, W.; Javed, T.; Park, S.; et al. Ignition of alkane-rich FACE gasoline fuels and their surrogate mixtures. Proc. Combust. Inst. 2015, 35, 249-57.

(38) Ahmed, A.; Goteng, G.; Shankar, V. S. B.; Al-Qurashi, K.; Roberts, W. L.; Sarathy, S. M. A computational methodology for formulating gasoline surrogate fuels with accurate physical and chemical kinetic properties. Fuel 2015, 143, 290-300.

(39) Sarathy, S. M.; Kukkadapu, G.; Mehl, M.; et al. Compositional effects on the ignition of FACE gasolines. Combust. Flame 2016, 169, 171-193.

(40) Curran, H. J.; Gaffuri, P.; Pitz, W. J.; Westbrook, C. K.; Leppard, W. R. Autoignition chemistry in a motored engine: an experimental and kinetic modeling study. Symp. (Int.) Combust.. [Proc.] 1996, 26, 266977.

(41) Mehl, M.; Faravelli, T.; Giavazzi, F.; Ranzi, E.; Scorletti, P.; Tardani, A.; et al. Detailed chemistry promotes understanding of octane numbers and gasoline sensitivity. Energy Fuels 2006, 20, 2391-8.
(42) Griffiths, J. F.; Halford-Maw, P. A.; Mohamed, C. Spontaneous ignition delays as a diagnostic of the propensity of Alkanes to cause Engine Knock. Combust. Flame 1997, 111, 327-337.

(43) Sarathy, S. M.; Javed, T.; Karsenty, F.; Heufer, A.; Wang, W.; Park, S.; et al. A comprehensive combustion chemistry study of 2,5dimethylhexane. Combust. Flame 2014, 161, 1444-59.

(44) Badra, J.; Bokhumseen, N.; Mulla, N.; Sarathy, S. M.; Farooq, A.; Kalghatgi, G.; Gaillard, P. A methodology to relate octane numbers of binary and ternary n-heptane, iso-octane and toluene mixtures with simulated ignition delay times. Fuel 2015, 160, 458. American Petroleum Institute. Knocking Characteristics of Pure Hydrocarbons; API, 1958.

(45) American Petroleum Institute. Technical Data Book - Petroleum Refining, 5th ed.; API, 1997.

(46) Mehl, M.; Vanhove, G.; Pitz, W.; Ranzi, E. Oxidation and combustion of the n-hexene isomers: $A$ wide range kinetic modeling study. Combust. Flame 2008, 155, 756-772.

(47) Reaction design. CHEMKIN-PRO. San Diego, CA, 2011.

(48) Goodwin, D. G.; Moffat, H. K.; Speth, R. L. Cantera: An ObjectOriented Software Toolkit for Chemical Kinetics, Thermodynamics, and Transport Processes, Version 2.2.0; 2015; http://www.cantera.org.

(49) Goteng, G. L.; Speight, M.; Nettyam, N.; Farooq, A.; Frenklach, M.; Sarathy, S. M. A Hybrid Cloud System for Combustion Kinetics Simulation, 23rd ed.; International Symposium on Gas Kinetics and Related Phenomena: Hungary, 2014.

(50) Li, S.; Sarathy, S. M.; Davidson, D. F.; Hanson, R. K. Shock tube and modeling study of 2,7-dimethyloctane pyrolysis and oxidation. Combust. Flame 2015, 162, 2296.

(51) Park, S.; Mannaa, O.; Khaled, F.; Bougacha, R.; Mansour, M. S.; Farooq, A. A comprehensive experimental and modeling study of 2methylbutanol combustion. Combust. Flame 2015, 162, 2166.

(52) Sarathy, S. M.; Westbrook, C. K.; Mehl, M.; Pitz, W. J.; Togbé, C.; Dagaut, P. Comprehensive chemical kinetic modeling of the oxidation of 2-methylalkanes from C7 to C20. Combust. Flame 2011, 158 (12), 2338-2357.

(53) Sarathy, S. M.; Javed, T.; Karsenty, F.; Heufer, A.; Wang, W.; Park, S. A comprehensive combustion chemistry study of 2,5dimethylhexane. Combust. Flame 2014, 161, 1444.

(54) Wang, W.; Li, Z.; Oehlschlaeger, M. A.; Healy, D.; Curran, H. J.; Sarathy, S. M. An experimental and modeling study of the autoignition of 3-methylheptane. Proc. Combust. Inst. 2013, 34 (1), 335-343.

(55) Galvin, H. P. The Levenberg-Marquardt Method for Nonlinear Least Squares Curve-Fitting Problems; May 4, 2016.

(56) MATLAB Help > Robust methods of curve fitting.

(57) Morgan, Neal; Smallbone, Andrew; Bhave, Amit; Kraft, Markus; Cracknell, Roger; Kalghatgi, Gautam Mapping surrogate gasoline compositions into RON/MON space. Combust. Flame 2010, 157 (no. 6), 1122-1131.

(58) Andrae, Johan CG. Development of a detailed kinetic model for gasoline surrogate fuels. Fuel 2008, 87 (no.10), 2013-2022.

(59) Mittal, Vikram; Heywood, John B.; William, H. Green The Underlying Physics and Chemistry behind Fuel Sensitivity. SAE Int. I. Fuel Lubr. 2010, 3, 256-265.

(60) Kalghatgi, G.; Babiker, H.; Badra, J. A Simple Method to Predict Knock Using Toluene, N-Heptane and Iso-Octane blends (TPRF) as Gasoline Surrogates. SAE Int. I. Engines 2015, 8 (2), 505. Merchant, S. S.; Goldsmith, C. F.; Vandeputte, A. G.; Burke, M. P.; Klippenstein, S. J.; Green, W. H. Understanding low-temperature first-stage ignition delay: Propane. Combust. Flame 2015, 162, 3658-3673.

(61) Lapuerta, M. N.; Hernández, J. J.; Sarathy, S. M. Effects of methyl substitution on the auto-ignition of C16 alkanes. Combust. Flame 2016, 164, 259-269.

(62) Westbrook, C. Oxidation and combustion of the n-hexene isomers: A wide range kinetic modeling study. Proc. Combust. Inst. 2000, 28, $1563-1577$.

(63) Zhang, P.; Ji, W.; He, T.; He, X.; Wang, Z.; Bin Yang; Law, C. K. First-stage ignition delay in the negative temperature coefficient behavior: Experiment and simulation. Combust. Flame 2016, 167, 1-10. 
(64) Zádor, J.; Taatjes, C. A.; Fernandes, R. X. Kinetics of elementary reactions in low-temperature autoignition chemistry. Prog. Energy Combust. Sci. 2011, 37 (4), 371-421.

(65) Curran, H.; Gaffuri, P.; Pitz, W.; Westbrook, C. A comprehensive modeling study of n-heptane oxidation. Combust. Flame 1998, 114 (12), 149-177.

(66) Curran, H.; Gaffuri, P.; Pitz, W.; Westbrook, C. A comprehensive modeling study of iso-octane oxidation. Combust. Flame 2002, 129 (3), 253-280.

(67) Vuilleumier, D.; Kozarac, D.; Mehl, M.; Saxena, S.; Pitz, W. J.; Dibble, R. W. Intermediate temperature heat release in an HCCI engine fueled by ethanol/n-heptane mixtures: An experimental and modeling study. Combust. Flame 2013, 161, 680.

(68) Wang, Z.; Sarathy, S. M. Third $\mathrm{O}_{2}$ addition reactions promote the low-temperature auto-ignition of n-alkanes. Combust. Flame 2016, 165, 364-372.

(69) Wang, Z.; Zhang, L.; Moshammer, K.; et al. Additional chainbranching pathways in the low-temperature oxidation of branched alkanes. Combust. Flame 2016, 164, 386-396.

(70) Westbrook, C. K.; Pitz, W. J.; Sarathy, S. M.; Mehl, M. Detailed chemical kinetic modeling of the effects of $C C$ double bonds on the ignition of biodiesel fuels. Proc. Combust. Inst. 2013, 34 (2), 3049-3056.

(71) Ray, D. J. M.; Waddington, D. J. Gas phase oxidation of alkenesPart II. The oxidation of 2-methylbutene-2 and 2,3-dimethylbutene-2. Combust. Flame 1973, 20, 327-334.

(72) Sway, M. I.; Waddington, D. J. Reactions of oxygenated radicals in the gas phase. Part 12. The reactions of isopropylperoxyl radicals and alkenes. I. Chem. Soc., Perkin Trans. 2 1983, 139-143.

(73) Vanhove, G.; Petit, G.; Minetti, R. Experimental study of the kinetic interactions in the low-temperature autoignition of hydrocarbon binary mixtures and a surrogate fuel. Combust. Flame 2006, 145, 521532.

(74) Metcalfe, W. K.; Dooley, S.; Dryer, F. L. Comprehensive detailed chemical kinetic modeling study of toluene oxidation. Energy Fuels 2011, $25,4915-4936$.

(75) Roubaud, A.; Lemaire, O.; Minetti, R; Sochet, L. R. High pressure auto-ignition and oxidation mechanisms of o-xylene, o-ethyltoluene, and n-butylbenzene between 600 and $900 \mathrm{~K}$. Combust. Flame 2000, 123, 561-571.

(76) Javed, Tamour; Lee, Changyoul; Mohammed, AlAbbad; Khalil, Djebbi; Mohamed, Beshir; Jihad, Badra; Curran, Henry; Farooq, Aamir Ignition studies of $\mathrm{n}$-heptane/iso-octane/toluene blends. Combust. Flame 2016, 171, 223-233.

(77) Kalghatgi, G. T. Developments in internal combustion engines and implications for combustion science and future transport fuels. Proc. Combust. Inst. 2015, 35, 101-115.

(78) Battin-Leclerc, F. Detailed chemical kinetic models for the lowtemperature combustion of hydrocarbons with application to gasoline and diesel fuel surrogates. Prog. Energy Combust. Sci. 2008, 34, 440-498.

(79) Zhang, F.; Dibble, T. S. Effects of Olefin Group and Its Position on the Kinetics for Intramolecular H-Shift and $\mathrm{HO}_{2}$ Elimination of Alkenyl Peroxy Radicals. I. Phys. Chem. A 2011, 115, 655-663. 